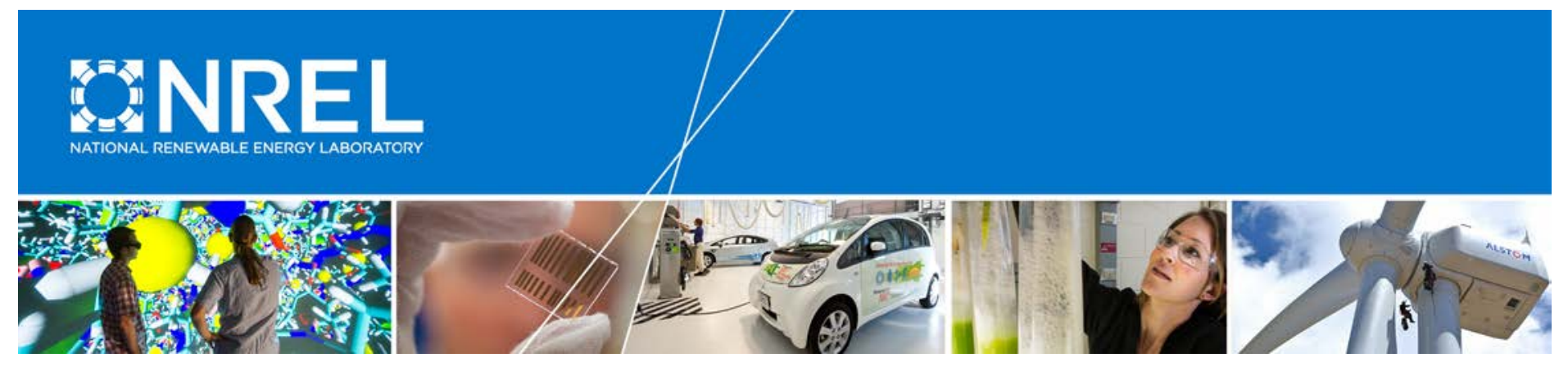

\title{
Hybridizing a Geothermal Plant with Solar and Thermal Energy Storage to Enhance Power Generation
}

Joshua D. McTigue, Guangdong Zhu, and Craig Turchi National Renewable Energy Laboratory

Greg Mungas, Nick Kramer, and John King Hyperlight Energy

Jose Castro

Coso Operating Company

NREL is a national laboratory of the U.S. Department of Energy Office of Energy Efficiency \& Renewable Energy Operated by the Alliance for Sustainable Energy, LLC

This report is available at no cost from the National Renewable Energy Laboratory (NREL) at www.nrel.gov/publications.

Technical Report

NREL/TP-5500-70862

June 2018 


\title{
Hybridizing a Geothermal Plant with Solar and Thermal Energy Storage to Enhance Power Generation
}

\author{
Joshua D. McTigue, Guangdong Zhu, \\ and Craig Turchi \\ National Renewable Energy Laboratory
}

Greg Mungas, Nick Kramer, and John King Hyperlight Energy

Jose Castro

Coso Operating Company

\section{Suggested Citation}

McTigue, Joshua D., Guangdong Zhu, Craig Turchi, Greg Mungas, Nick Kramer, John King, and Jose Castro. 2018. Hybridizing a Geothermal Plant with Solar and Thermal Energy Storage to Enhance Power Generation. Golden, CO: National Renewable Energy Laboratory. NREL/TP-5500-70862.

NREL is a national laboratory of the U.S. Department of Energy Office of Energy Efficiency \& Renewable Energy Operated by the Alliance for Sustainable Energy, LLC

This report is available at no cost from the National Renewable Energy Laboratory (NREL) at www.nrel.gov/publications.

National Renewable Energy Laboratory 15013 Denver West Parkway Golden, CO 80401

303-275-3000 • www.nrel.gov
Technical Report

NREL/TP-5500-70862

June 2018

Contract No. DE-AC36-08GO28308 


\section{NOTICE}

This report was prepared as an account of work sponsored by an agency of the United States government. Neither the United States government nor any agency thereof, nor any of their employees, makes any warranty, express or implied, or assumes any legal liability or responsibility for the accuracy, completeness, or usefulness of any information, apparatus, product, or process disclosed, or represents that its use would not infringe privately owned rights. Reference herein to any specific commercial product, process, or service by trade name, trademark, manufacturer, or otherwise does not necessarily constitute or imply its endorsement, recommendation, or favoring by the United States government or any agency thereof. The views and opinions of authors expressed herein do not necessarily state or reflect those of the United States government or any agency thereof.

This report is available at no cost from the National Renewable Energy Laboratory (NREL) at www.nrel.gov/publications.

Available electronically at SciTech Connect http:/www.osti.gov/scitech

Available for a processing fee to U.S. Department of Energy and its contractors, in paper, from:

U.S. Department of Energy

Office of Scientific and Technical Information

P.O. Box 62

Oak Ridge, TN 37831-0062

OSTI http://www.osti.gov

Phone: 865.576.8401

Fax: 865.576.5728

Email: reports@osti.gov

Available for sale to the public, in paper, from:

U.S. Department of Commerce

National Technical Information Service

5301 Shawnee Road

Alexandria, VA 22312

NTIS http://www.ntis.gov

Phone: 800.553 .6847 or 703.605 .6000

Fax: 703.605.6900

Email: orders@ntis.gov 


\section{Acknowledgments}

This work was supported by the U.S. Department of Energy under Contract Number DE-AC36$08 G O 29308$ to the National Renewable Energy Laboratory (NREL). The authors gratefully acknowledge Mike Erbes for assisting with the off-design steam turbine modeling and the Naval Geothermal Program Office, including Andrew Sabin, David Meade, Michael Lazaro, and Kelly Blake, for their contributions.

Any questions or inquiries should be addressed to the technical lead, Dr. Guangdong Zhu. His contact information is below. Dr. Zhu is with the NREL Thermal Sciences Group, supporting the Geothermal Technology Program and Concentrating Solar Power Program. His contact information is Guangdong.Zhu@nrel.gov, phone: 303-275-4497, and fax: 303-630-2108. 


\section{Executive Summary}

Geothermal power plants typically experience a decrease in power generation over time due to a reduction in the geothermal resource temperature, pressure, or mass flow rate. This report explores methods to hybridize a double-flash geothermal plant with a concentrating solar power collector field. The solar field generates heat that is added to geothermal fluid and then recirculated through the steam turbine, thereby increasing the mass flow rate and pressure and consequently the power generation. The objective is to augment the geothermal plant power generation from its off-design operating condition at low cost.

A model of a double-flash geothermal power plant is developed, and results are validated against the operation of the Coso geothermal field, in China Lake, California. The concentrating solar system is based on linear Fresnel reflectors developed by Hyperlight Energy Ltd. Data for a wide variety of potential heat transfer fluids has been collected. Thermal storage, in the form of two liquid storage tanks, is included with the objective of maximizing the electricity generated by the system. The most suitable fluid (in terms of thermal properties and cost) was determined to be either a mineral oil such as Xceltherm 600 or a synthetic fluid such as Therminol VP-1.

Several different methods of adding solar heat are considered, and a computer model is developed to compare the performance. Practicalities, such as the risk of mineral deposition in the pipes and heat exchangers, are also considered. The best method of integrating the solar heat involves extracting fluid from the first flash tank, heating it with the solar heat, and recirculating it into the high-pressure steam turbine. This configuration can achieve a solar-heat-to-electricalwork conversion efficiency of $24.3 \%$.

Annual simulations were undertaken for this system to determine the optimal sizing of the solar field and the thermal storage. The system was sized to increase the power output from $22.2 \mathrm{MWe}$ to 24.2 MWe and the levelized cost of electricity (LCOE) was calculated. The LCOE is not a suitable metric for assessing the optimal storage duration: storage merely shifts the time that the energy is produced, and as a result, the LCOE always increases with storage duration. (In this study, the power plant receives a fixed price for electricity, regardless of the time and demand when it is dispatched.) The optimal storage duration is found by considering the storage capital cost per unit energy dispatched from the storage. For instance, large storage tanks have economies of scale (and low capital costs per unit energy capacity), but this is at the expense of the storage tank rarely being fully charged.

An optimal solar field size exists: increasing the solar field size produces more energy and reduces the LCOE. However, if the solar field size is increased further, not all the energy can be absorbed by the power block and must be curtailed, at which point the LCOE begins to increase. The optimal solar field size depends on the duration of thermal storage available: a solar multiple of 2 has an optimal storage duration of 3 hours, while for a solar multiple of 3 the optimal storage size is 10 hours.

Two different heat transfer fluids, a mineral oil and a synthetic oil, were compared. Mineral oils have lower maximum operating points, but low vapor pressures. On the other hand, synthetic fluids can operate at higher temperatures, thereby potentially reducing the storage size at the expense of higher vapor pressures, meaning that storage vessels should be pressurized. Results 
indicate that a diphenyl oxide / biphenyl based synthetic fluid is currently a more cost-effective solution.

The LCOE results were compared to an equivalent photovoltaic array (PV) with battery energy storage (BES) and are summarized in the table below. The hybrid plant has an LCOE comparable to photovoltaics when there is no storage. However, the hybrid plant achieves lower LCOEs than PV+BES once storage is included, because thermal storage is relatively inexpensive compared to batteries. Furthermore, the replacement rate of the heat transfer fluid is low (and therefore low in cost) compared to the cost of replacing batteries that currently have a 10- to 15year lifetime.

Table: LCOE comparison of hybrid geothermal-solar-storage with photovoltaic cells with battery storage.

\begin{tabular}{ccrrr} 
& & \multicolumn{2}{c}{ LCOE, \$ / $\mathrm{kWh}_{\mathrm{e}}$} \\
\cline { 4 - 5 } $\begin{array}{c}\text { Annual energy } \\
\text { generation, GWh }\end{array}$ & $\begin{array}{c}\text { Solar } \\
\text { multiple }\end{array}$ & $\begin{array}{c}\text { Storage } \\
\text { duration, } \mathrm{h}\end{array}$ & Hybrid plant & PV+BES \\
\hline \multirow{2}{*}{6.98} & 2 & 0 & $0.067 \pm 0.011$ & $0.062 \pm 0.014$ \\
& & 3 & $0.081 \pm 0.011$ & $0.112 \pm 0.024$ \\
9.34 & & 0 & $0.076 \pm 0.012$ & $0.062 \pm 0.014$ \\
& 3 & 10 & $0.091 \pm 0.011$ & $0.172 \pm 0.035$ \\
& & & &
\end{tabular}




\section{Table of Contents}

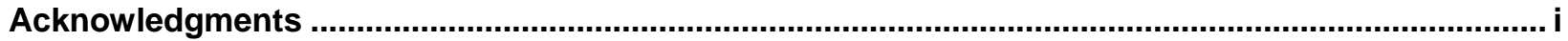

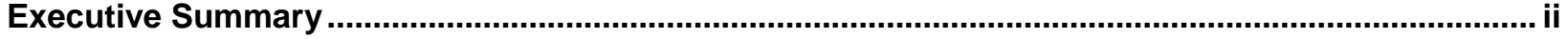

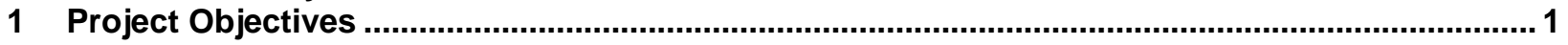

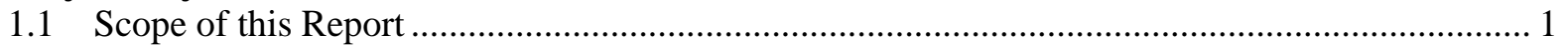

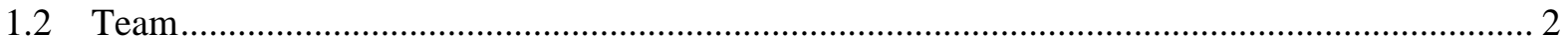

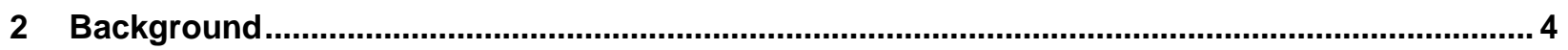

2.1 Geothermal Power Plant at Coso, China Lake, California ............................................................ 4

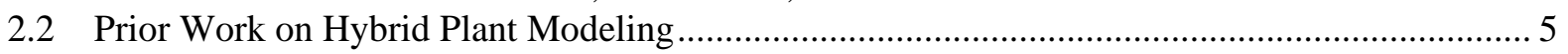

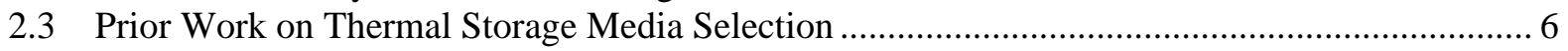

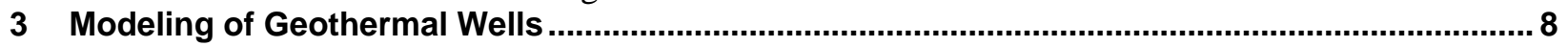

4 Modeling Off-Design Steam Turbines .................................................................................... 9

4.1 Stodola's Ellipse and Off-Design Steam Turbine Modeling................................................ 9

4.2 Combined Behavior of Geothermal Well Characteristics and Steam Turbine Characteristics ... 10

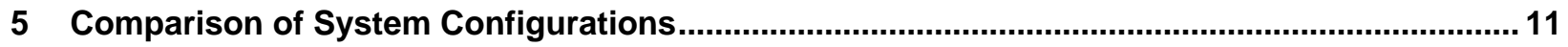

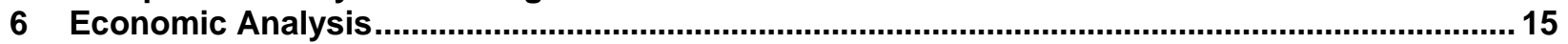

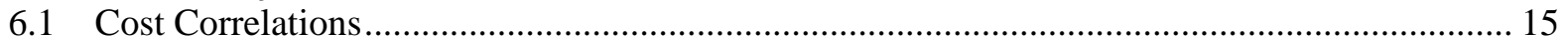

6.2 Levelized Cost of Electricity and Internal Rate of Return ........................................................ 16

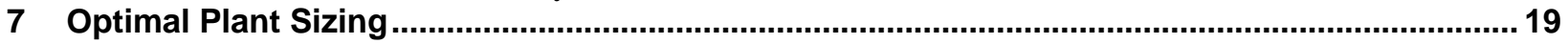

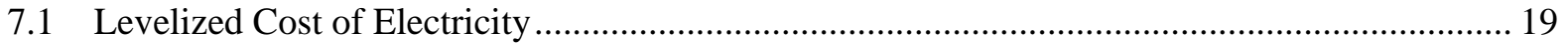

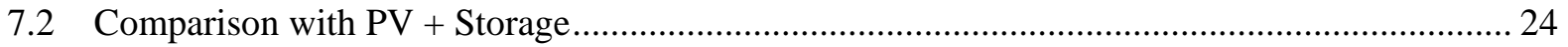

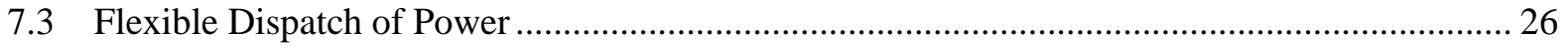

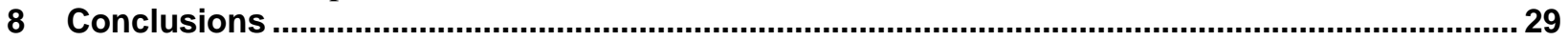

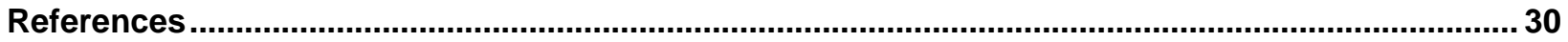

Appendix A .

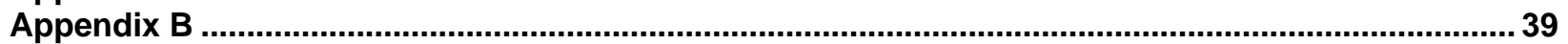




\section{List of Figures}

Figure 1: Map of the USA showing locations of high solar irradiance and geothermal temperatures at a depth of 3000 m. Data from National Solar Radiation Database ("National Solar Radiation

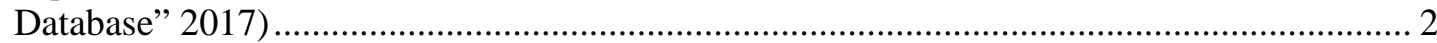

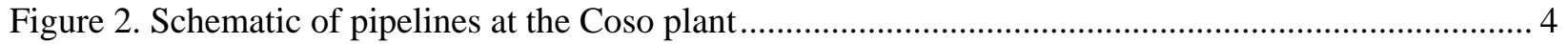

Figure 3. Hybrid plant with two-tank direct thermal storage ................................................................. 5

Figure 4. Solar heat can be added at different points in the geothermal power plant ............................... 13

Figure 5. Power flows in the hybrid power plant for the summer solstice and winter solstice................... 20

Figure 6. Effect of solar field size and thermal storage sizing on the levelized cost of energy ................. 21

Figure 7. Utilization and cost per unit energy dispatched of thermal storage............................................ 23

Figure 8. Curves showing the price multiplier required for a hybrid system with a given storage duration to achieve an internal rate of return of $10 \%$. The price multiplier is the increased price that stored energy is dispatched at. Shaded bands show the uncertainty. .................................... 28

\section{List of Tables}

Table 1. Chemistry of Brine at Coso Geothermal Field.

Table 2. Design and Off-Design Inputs and Performance Data Used in the Model of a Two-Stage Steam

Turbine Unit

Table 3. Advantages and Disadvantages of Various Heat Transfer Fluid Groups ..................................... 7

Table 4. Pressure-Mass Flow Characteristic for a Geothermal Well ...................................................... 8

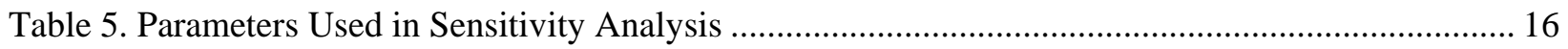

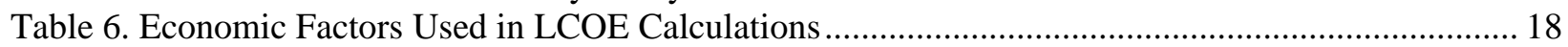

Table 7. Operating Point of Hybrid Plant Using FT1 Configuration...................................................... 19

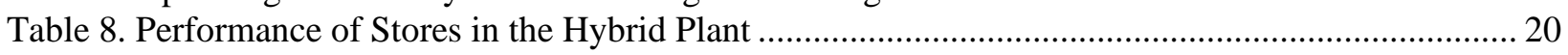

Table 9. Costs and Sizes of Thermal Stores at Different Temperatures for 4 Hours of Storage ................ 22

Table 10. Hybrid Plant Economics for Different Solar Multiples, With and Without Optimally

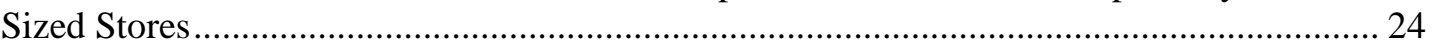

Table 11. LCOE of Solar PV Plus Storage Taken from the Literature .................................................... 25

Table 12. LCOE for Solar PV Plus Storage Estimated Using the System Advisor Model, Assuming a Lifetime of 30 Years 


\section{Project Objectives}

Concentrating solar power (CSP) collectors can be used to produce heat that will supplement an underperforming geothermal plant. Increasing the turbine inlet mass flow rates and pressures by solar will then allow the geothermal turbines to operate closer to the design operating conditions, thereby increasing the efficiency and power production of the overall plant. In addition, thermal storage may be incorporated so that the added solar thermal energy can boost the power generation of the geothermal/solar hybrid plant independent of intermittent solar irradiance. Thermal storage enables energy from the hybrid plant to be time-shifted to periods in the day where utility market demand and energy rates are higher.

The objective of this project is to identify cost-effective thermal storage systems for a geothermal/solar hybrid system in order to increase the plant dispatchability. Furthermore, an optimal quantity of thermal storage will also be determined to achieve the best economics of a geothermal/solar hybrid plant. The National Renewable Energy Laboratory (NREL) is working with Hyperlight Energy and Coso Operating Company to develop techno-economic models of such a system.

\subsection{Scope of this Report}

In this report, a thermodynamic model of the hybrid geothermal-solar-storage plant is developed. The geothermal well model is improved compared to previous efforts and includes a characteristic relationship between pressure and mass flow rate. The steam turbine off-design models are improved to use a control strategy known as "sliding pressure” control.

We concentrate on the retrofit of an underperforming double-flash geothermal power plant: production fluids are flashed and the resulting steam powers a steam turbine. Hybrid plants require good solar and geothermal resources, and Figure 1 indicates that the most suitable locations in the US are the Western states, and are primarily dependent on the geothermal resource location.

The installed geothermal capacity in the USA is $3134 \mathrm{MWe}$, most of which is concentrated in California and Nevada, see Figure 1. Flash plants comprise 29\% of US geothermal capacity, and notably $90 \%$ of US flash plant capacity is over 25 years old, indicating that many existing plants may be experiencing the effects of resource decline. The opportunity to explore resource decline mitigation currently exists in the US, and the results may have benefits internationally as flash plants make up 65\% of the world's total installed capacity of 11929 MWe.

Geothermal resources typically experience a reduction in the temperature, pressure, or mass flow rate of its production fluids over time, leading to decreased power generation and underutilized equipment. If a Power Purchase Agreement exists plant operators may be subject to additional fees for not producing agreed amounts of power (Wendt and Mines 2014). The extent of any resource decline is unique to that geothermal field. A study of geothermal power plants in California and Nevada found that flash plants typically experienced a temperature decrease of $0.8 \%$ per year, while the value was $0.5 \%$ for binary plants (Snyder et al. 2017). Underperforming 
plants may be brought back to full capacity by the addition of thermal heat. The unused capacity of the geothermal plant provides an opportunity to install a concentrating solar plant at reduced cost since investment in a power unit and condenser are not required. Integrating thermal storage provides the plant with flexibility and dispatchability.

In this technical report, several methods of integrating solar heat into a geothermal power plant are investigated. A thermodynamic model of the system is developed, and annual calculations are undertaken to evaluate the Levelized Cost of Electricity (LCOE). The hybrid plant LCOE is compared to an equivalent photovoltaic array with batteries. The hybrid system includes twotank liquid thermal energy storage which is a technologically deployable storage system.

An economic model of the hybrid power plant is developed, and the economic characteristics of the system are analyzed. The economic performance of the hybrid plant is compared to a corresponding solar photovoltaic (PV) plant with battery storage in the California market.

a

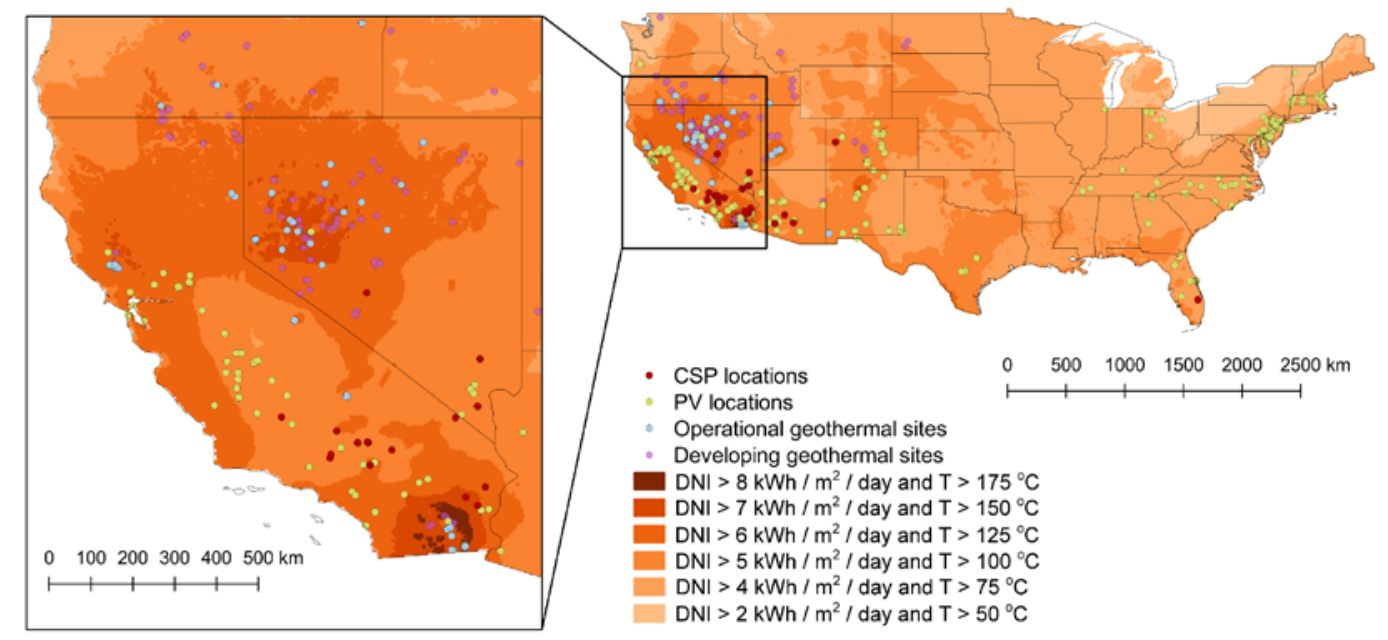

Figure 1: Map of the USA showing locations of high solar irradiance and geothermal temperatures at a depth of $3000 \mathrm{~m}$. Data from National Solar Radiation Database ("National Solar Radiation Database" 2017)

\subsection{Team}

Hyperlight Energy is a CSP company whose business charter is to develop/commercialize a lowcost CSP collector system ultimately for providing heat for solar thermal/geothermal hybrid power plants, process heat applications (e.g., enhanced oil recovery), and solar thermal power generation. Hyperlight's CSP collector system utilizes a linear Fresnel configuration. This linearFresnel configuration consists of mirrors mounted in low-cost, precision plastic extrusions, which are integrated into raft assemblies and deployed on low-cost, sealed waterbeds. Hyperlight's CSP collector technology has been developed under private equity investment, government grant, and commercial funding. 
By adopting the technology Hyperlight Energy is developing, NREL performed technical and economic analysis in the following areas: (1) ensuring that bundling geothermal and solar thermal energy with thermal energy storage for time-shifting to more profitable periods of time on the grid remains within the infrastructure capabilities of the geothermal plants, and (2) helping assess and evaluate candidate medium temperature $\left(250-395^{\circ} \mathrm{C}, 480-740^{\circ} \mathrm{F}\right)$ thermal storage options.

NREL and Hyperlight are working with the Coso Operating Company to conduct a feasibility study of solar hybridization at the Coso Geothermal Plant at China Lake, California. The field is located within the Naval Air Weapons Station (NAWS) and is currently operated by Coso Operating Company. The Coso Operating Company provided data and expertise about the operation of the geothermal fields and the possible integration of the CSP and storage systems. The Naval Geothermal Program Office has also provided support and contributions. 


\section{Background}

\subsection{Geothermal Power Plant at Coso, China Lake, California}

The power generating facility at Coso consists of four geothermal power plants that have a total of nine 30-MWe turbine-generator sets for a total of $270 \mathrm{MW}_{\mathrm{e}}$ of rated capacity. The plants were constructed by Mitsubishi and Fuji from 1987 through 1989. Between 80 and 90 production wells operate at a given time, producing a mass flow rate of more than 14 million pounds per hour. Depending on the volume of fluid that needs to be handled and where pressure support is required, the Coso field can use between 30 and 40 injection wells. The power plants utilize double-flash technology for steam extraction due to the hightemperature fluids. Wellhead pressures range from 85-500 psig. Produced fluids are moderately saline chloride brines with total dissolved solids from 10,000-20,000 ppm, with a 5-8 pH. Noncondensable gases account for $6 \%$ of the gas fraction, with $98 \%$ of that from carbon dioxide $\left(\mathrm{CO}_{2}\right)$. More details are provided in Table 1.

The proposed location for CSP hybridization is on the East Flank, which provides brine to two turbine units (units 4 and 5), as shown in Figure

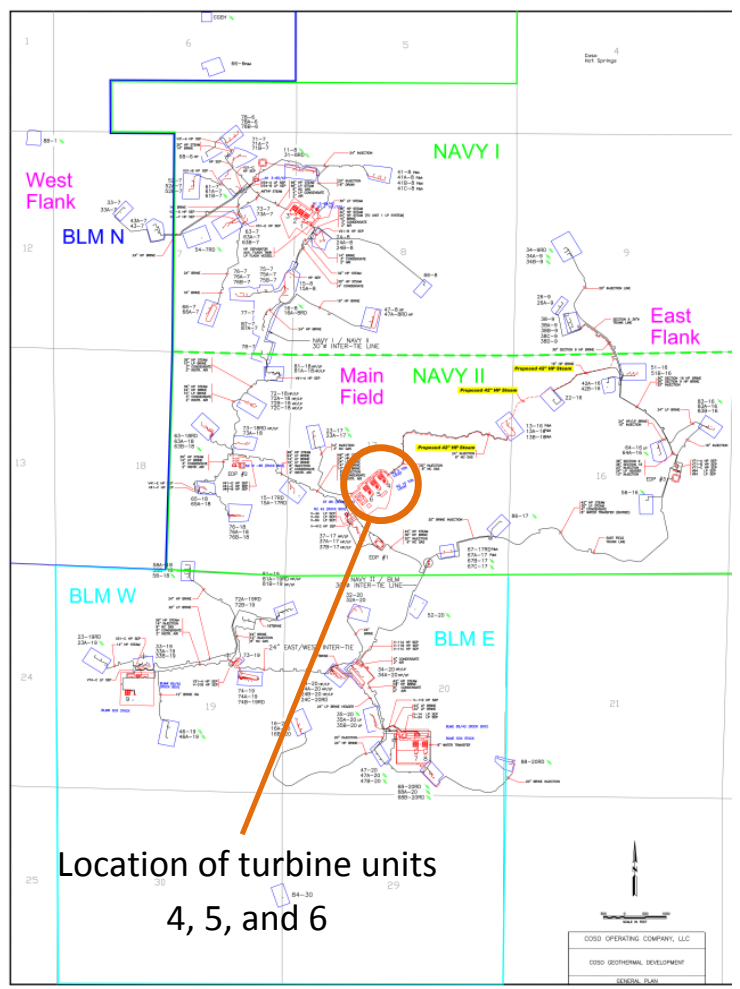

Figure 2. Schematic of pipelines at the Coso plant 2. The design operating conditions for these $30 \mathrm{MW}$ e turbines are given in Table 2. Operational data provided by the Coso Operating Company were used to define typical operating conditions, which are also shown in Table 2.

Table 1. Chemistry of Brine at Coso Geothermal Field

\begin{tabular}{lr} 
Chemistry & Concentration, ppm \\
\hline Sodium & $3,000-5,000$ \\
Potassium & $600-1,000$ \\
Calcium & $80-300$ \\
Lithium & $20-50$ \\
Arsenic & $10-20$ \\
Boron & $150-500$ \\
Chlorine & $5,000-10,000$ \\
Fluorine & $0-5$ \\
Silicon dioxide & $500-700$ \\
Sulfate & $30-80$ \\
Bicarbonate & $60-70$
\end{tabular}


Table 2. Design and Off-Design Inputs and Performance Data Used in the Model of a Two-Stage Steam Turbine Unit

\begin{tabular}{|c|c|c|c|c|c|}
\hline & & \multicolumn{2}{|c|}{ Design conditions } & \multicolumn{2}{|c|}{ Current operating conditions } \\
\hline & & High pressure & Low pressure & High pressure & Low pressure \\
\hline Mass flow & $\mathrm{kg} \mathrm{s}^{-1}$ & 48.0 & 25.0 & 43.8 & 7.1 \\
\hline Temperature & ${ }^{\circ} \mathrm{C}$ & 169.2 & 132.5 & 159.8 & 98.3 \\
\hline Inlet pressure & bar & 6.3 & 1.4 & 5.7 & 0.95 \\
\hline Gross power & $\mathrm{MW}_{\mathrm{e}}$ & \multicolumn{2}{|c|}{29.6} & \multicolumn{2}{|c|}{22.5} \\
\hline Net power & $M W_{e}$ & \multicolumn{2}{|c|}{29.4} & \multicolumn{2}{|c|}{22.2} \\
\hline Efficiency & $\%$ & \multicolumn{2}{|c|}{19.7} & \multicolumn{2}{|c|}{16.9} \\
\hline
\end{tabular}

\subsection{Prior Work on Hybrid Plant Modeling}

Initial work developed a concept for the hybrid geothermal-solar-storage plant, considered the addition of solar heat at several locations, and investigated the use of different thermal storage technologies (McTigue et al. 2017). After considering practical constraints, a hybrid design was selected and is illustrated in Figure 3. The solar field heats a heat transfer fluid (HTF), which can then be stored in liquid tanks. The HTF transfers heat to the geothermal system in a heat exchanger (HX). The heat is added to a fraction of the unflashed brine that would otherwise be injected into the geothermal reservoir. The heated brine is mixed with the geothermal production fluids, which then enter the flash tanks.

Preliminary models of the hybrid system were developed in the flow-sheeting software tool IPSEpro.

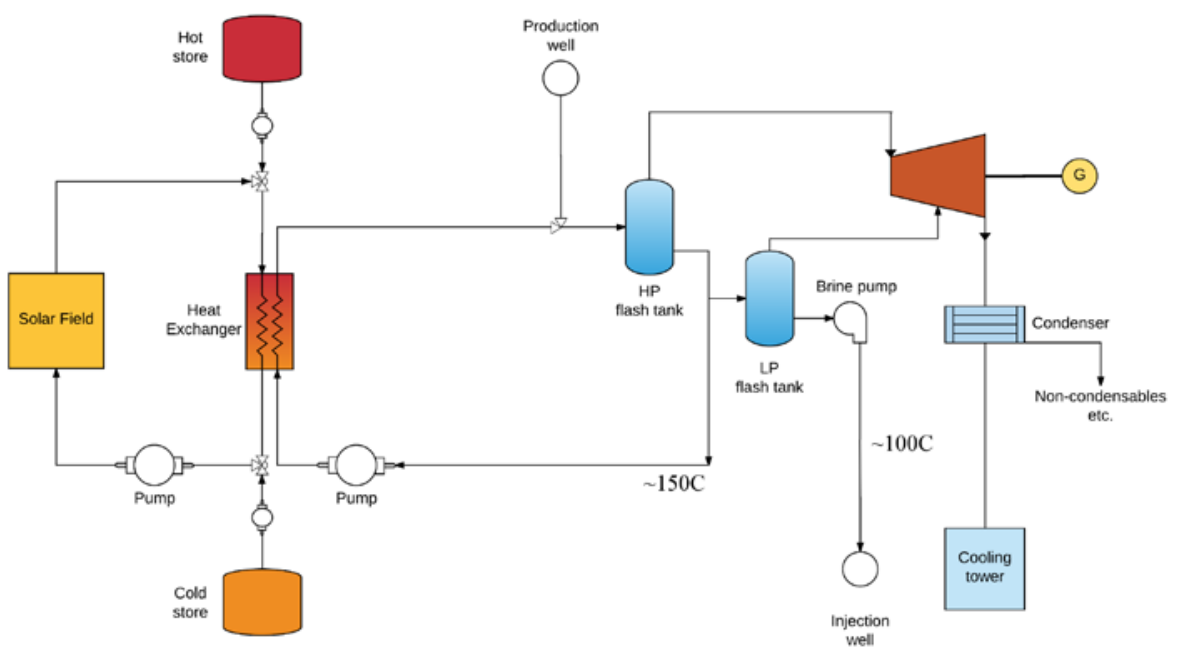

Figure 3. Hybrid plant with two-tank direct thermal storage 


\subsection{Prior Work on Thermal Storage Media Selection}

A list of 47 thermal storage media candidates was compiled. Fluid groups included water, mineral oils, synthetic fluids, molten salts, glycols, and silicone oils. The thermal properties of these commercial fluids were tabulated, and graphics compared. Cost data were also collected, and this information is tabulated in Appendix A.

Using this information, the capital costs of two-tank direct storage systems were calculated for a range of temperatures and storage durations. The eight most promising HTFs were selected, and other factors such as health and environmental impacts were considered. In summary:

1. Mineral oils are promising candidates due to low cost, low vapor pressure, high heat capacities, and low health and environmental risks. Thermal degradation may be an issue, and further discussion with suppliers is recommended.

2. Synthetic fluids can operate at high temperatures. However, they have high vapor pressures, so it is generally cheaper to use a mineral oil at $250^{\circ} \mathrm{C}$ than a synthetic fluid at $350^{\circ} \mathrm{C}$. The ability to run at high temperatures means that a tube-in-concrete system could be used, which would be around two-thirds of the cost of the two-tank direct storage systems. It should be noted that the cost for the tube-in-concrete system is based on a quote for large production volumes from a single vendor.

3. Molten salts have been widely used in CSP and thermal storage applications and have high heat capacities and low vapor pressures. However, they have high freezing points and viscosities.

4. Water and glycols have excellent thermal properties but a limited operating temperature range without pressurization. Degradation and corrosion may be an issue with glycols, and therefore, it is generally cheaper and simpler to use distilled water.

5. Silicone oils were found to be unsuitable due to high costs and poor thermal characteristics.

6. There remains uncertainty about the degradation rates of the fluids and the extent to which corrosion is a factor.

Advantages and disadvantages of different fluid groups are summarized in Table 3.

Out of the eight candidate fluids, it was decided that the most promising were a mineral oil known as Xceltherm 600 and a synthetic fluid known as Therminol VP-1. Therminol VP1 can operate at higher temperatures than the other fluids and, therefore, provide more flexibility for use in other systems. On the other hand, the high pour point of $12^{\circ} \mathrm{C}$ may place additional constraints on system design and require the installation of heaters. 
Table 3. Advantages and Disadvantages of Various Heat Transfer Fluid Groups

\begin{tabular}{|c|c|c|}
\hline Fluid group & Advantages & Disadvantages \\
\hline Mineral oils & $\begin{array}{ll}\text { - } & \text { Competitive upfront cost } \\
\text { - } & \text { Low vapor pressure so will not } \\
& \text { require pressure vessels } \\
\text { - } & \text { Low viscosities } \\
\text { - } & \text { Good volumetric heat capacities }\end{array}$ & $\begin{array}{l}\text { - } \quad \text { Lower operating temperatures than } \\
\text { molten salts or synthetic fluids } \\
\text { - Higher rates of oxidation and } \\
\text { decomposition than synthetic fluids } \\
\text { - Higher maintenance and operation } \\
\text { and maintenance (O\&M) cost }\end{array}$ \\
\hline $\begin{array}{l}\text { Synthetic } \\
\text { fluids }\end{array}$ & $\begin{array}{l}\text { - } \quad \text { High operating temperatures } \\
\text { - } \quad \text { mineral oils } \\
\text { - } \quad \text { Good volumetric heat capacities } \\
\text { - } \quad \text { Lowimilar to mineral oils) } \\
\text { - } \quad \text { \& cost }\end{array}$ & $\begin{array}{l}\text { - More expensive upfront } \\
\text { procurement cost than mineral oils } \\
\text { High vapor pressures, which require } \\
\text { higher-cost storage vessels, } \\
\text { particularly at high temperatures }\end{array}$ \\
\hline Silicone oils & - Good thermal stability & $\begin{array}{l}\text { - } \quad \text { Most expensive fluid group } \\
\text { - } \quad \text { vigh vapor pressures and } \\
\text { - } \quad \text { Low volumetric heat capacities } \\
\text { - } \quad \text { May gel above } 200^{\circ} \mathrm{C}\end{array}$ \\
\hline Molten salts & $\begin{array}{l}\text { - } \quad \text { Do not require pressurization } \\
\text { - High volumetric heat capacities } \\
\text { - } \quad \text { Widely used in CSP and thermal } \\
\text { storage } \\
\text { - Cost competitive }\end{array}$ & $\begin{array}{l}\text { - High freezing point so may require } \\
\text { additional equipment } \\
\text { - High viscosities increase pumping } \\
\text { costs }\end{array}$ \\
\hline Water & $\begin{array}{l}\text { - } \text { High heat capacity and thermal } \\
\text { - } \quad \text { Lonductivity } \\
\text { - } \text { Very low cost } \\
\text { - } \quad \text { Non-toxic and environmentally } \\
\text { friendly } \\
\text { - }\end{array}$ & $\begin{array}{l}\text { - High vapor pressures above } 100^{\circ} \mathrm{C} \\
\text { leads to higher storage costs and } \\
\text { pressure-related hazard mitigation } \\
\text { strategies (or a more limited } \\
\text { operating temperature range) } \\
\text { - Material design constraints to } \\
\text { address corrosion }\end{array}$ \\
\hline Glycols & $\begin{array}{l}\text { - High volumetric heat capacities and } \\
\text { - } \quad \text { Low viscosities } \\
\text { - } \quad \text { Lowest cost fluid group }\end{array}$ & $\begin{array}{l}\text { - } \quad \text { Limited temperature range } \\
\text { - } \quad \text { High vapor pressures } \\
\text { Thermal oxidation lowers } \mathrm{pH} \text { and } \\
\text { has corrosive products } \\
\text { Requires more maintenance and } \\
\text { has higher make-up rates than other } \\
\text { fluids }\end{array}$ \\
\hline
\end{tabular}




\section{Modeling of Geothermal Wells}

Previous work has assumed that geothermal fluid is produced at a constant mass flow rate, pressure, and temperature (McTigue et al. 2017). This was an unrealistic assumption to make because the mass flow rate and pressure are typically inversely proportional to one another. Furthermore, varying the operating point of the turbine or other surface equipment may affect the quantity of fluid that is drawn from the reservoir.

The pressure-mass flow rate characteristic curve of the well is assumed to follow a choked flow correlation, as proposed by DiPippo (Dipippo 2016), which can be written as

$$
\frac{\dot{m}}{\dot{m}_{\max }}=1+a_{1}\left(\frac{P}{P_{\max }}\right)+a_{2}\left(\frac{P}{P_{\max }}\right)^{2}+a_{3}\left(\frac{P}{P_{\max }}\right)^{3}
$$

Where $P_{\max }=17.8 \mathrm{bar}, m_{\max }=99.663 \mathrm{~kg} / \mathrm{s}, a_{1}=-0.02637, a_{2}=5.822 \times 10^{-3}$, and $a_{3}=-4.226 \mathrm{x}$ $10^{-4}$. However, this cubic expression demonstrates a non-physical inflexion point at high mass flow rates. In this case, it is more appropriate to use tabulated data (see Table 2) and cubic interpolation to find intermediate points.

The values of $P_{\max }$ and $m_{\max }$ were set at $P_{\max }=30 \mathrm{bar}, m_{\max }=125 \mathrm{~kg} / \mathrm{s}$ in order to match the design point requirements of the geothermal plant. The current operating point of the power plant was obtained by reducing the maximum mass flow rate to $m_{\max }=112 \mathrm{~kg} / \mathrm{s}$. The geothermal fluid was assumed to have a specific enthalpy of $1,500 \mathrm{~kJ} / \mathrm{kg}$, which is in line with typical enthalpies observed at Coso.

Table 4. Pressure-Mass Flow Characteristic for a Geothermal Well

\begin{tabular}{l|l}
$\dot{m} / \dot{m}_{\max }$ & $P / P_{\max }$ \\
\hline 0.000 & 1.00 \\
0.135 & 0.99 \\
0.339 & 0.98 \\
0.508 & 0.96 \\
0.678 & 0.90 \\
0.763 & 0.80 \\
0.950 & 0.55 \\
0.980 & 0.38 \\
0.990 & 0.19 \\
1.000 & 0.00
\end{tabular}

The salt content of geothermal production fluids is low, and the fluid can therefore accurately be modeled using water properties. 


\section{Modeling Off-Design Steam Turbines}

\subsection{Stodola's Ellipse and Off-Design Steam Turbine Modeling}

Off-design behavior of the steam turbine is modeled using Stodola's ellipse, which relates the mass flow rate and the inlet and outlet pressures through (Dixon and Hall 2010)

$\dot{m}\left(\sqrt{T_{01}}\right) / p_{01}=k\left[1-\left(p_{0 e} / p_{01}\right)^{2}\right]^{1 / 2}$

Where $\dot{m}$ is the mass flow rate, $T_{01}$ is the inlet temperature, $p_{01}$ is the inlet pressure, $p_{0 \text { e }}$ is the outlet pressure, and $k$ is a constant of proportionality. Assuming that $k$ is constant for all cases, off-design performance may be related to design performance with the following equation (Cooke 1985)

$$
\frac{\dot{m}}{\dot{m}_{\text {ref }}}\left(\sqrt{\frac{T_{01}}{T_{01, \text { ref }}}}\right) \frac{p_{01, \text { ref }}}{p_{01}}=\frac{\left[1-\left(p_{0 e} / p_{01}\right)^{2}\right]^{1 / 2}}{\left[1-\left(p_{0 e, \text { ref }} / p_{01, \text { ref }}\right)^{2}\right]^{1 / 2}}
$$

A variety of physical mechanisms lead to entropy generation in the steam turbine, as described in (Denton 2017). Rather than undertaking detailed stage-by-stage calculations, stages are grouped into sections, and correlations of each section efficiency are used to predict turbine performance. These correlations are based on experimental results from turbine units and from stage-by-stage calculations. The correlations were originally developed by Spencer-Cotton-Cannon (Spencer, Cotton, and Cannon 1974; Fuller and Stovall 1979), and the computer code was developed in (Choo and Staiger 1982) and implemented in IPSEpro.

Off-design performance of the steam turbine was validated against operational data provided by Coso Operating Company.

IPSEpro allows steam turbines to be operated by "sliding pressure" control or "throttling” control. In sliding pressure control, the turbine "reacts" to the operating point set by the rest of the system. For instance, the outlet pressure may be fixed by the condenser pressure. The inlet pressure then "floats" in response to variations in the system mass flow rate, in accordance with Stodola’s ellipse.

Throttling control can be considered as a valve before the turbine inlet. The mass flow rate and inlet and outlet pressures are still related by Stodola's ellipse. However, the throttle is used to select an inlet pressure that allows the required mass flow rate to be passed through the turbine. This requires the fluid pressure before the valve to be sufficiently high and leads to significant losses.

In the analysis of the hybrid plant, the condenser pressure is assumed to be fixed. This is a reasonable assumption because the condenser is water-cooled so that ambient conditions do not have a significant impact. 


\subsection{Combined Behavior of Geothermal Well Characteristics and Steam Turbine Characteristics}

The pressure-mass flow rate characteristics of the geothermal well and the steam turbine act in direct opposition to one another. For instance, increasing the mass flow rate into the steam turbine requires an increase in inlet pressure to pass the same volumetric flow rate. On the other hand, increasing the geothermal mass flow rate requires a decrease in the pressure of the production fluids.

The hybrid plant can overcome this constraint. For instance, reducing the mass flow rate of the geothermal production fluids increases the pressure of the fluid that reaches the turbine. The increased mass flow rate that is required can then be provided by recirculating some fluid and heating it with the solar field. There is some degree of freedom in choosing where fluid is extracted for recirculation, and these options are discussed below. 


\section{Comparison of System Configurations}

Solar heat can be added to the geothermal cycle in several locations, and several of these have been investigated in the literature. One of the first hybrid plants was proposed in 1979 by Mathur (Mathur 1979) who suggested that geothermal heat was used for feedwater heating and solar heat to boil water for use in a steam turbine. Mathur then proposed a similar cycle that included storage in molten salts, as well as several cycles that included fossil fuel burners. Mathur concluded at the time that hybrid plants demonstrated no economic advantages over standalone geothermal plants. Given recent advances in CSP and storage technology, now is an appropriate time to review this work. Handal et al. (Handal, Alvarenga, and Recinos 2007) considered four methods for adding solar heat to the Ahuachapán geothermal field in El Salvador. Heating the brine directly from the production well was ruled out because it required a larger HX. In a subsequent paper, Alvarenga et al. (Alvarenga, Handal, and Recinos 2008) discussed two of these methods. In the first approach, brine from the first separator is heated by thermal input from a solar field in an HX, and the generated steam enters the high-pressure (HP) turbine. This approach was reportedly tested successfully. In the second approach, the brine from the second flash stage is heated in the solar HX, and the lower-pressure steam enters the low-pressure (LP) turbine stage. The objective was to increase the power output of the field from 95 MWe to 97 MWe. The authors estimated that adding 2-3 MWe would require a solar field of around 30 acres that delivers an $\mathrm{HTF}$ at $225^{\circ} \mathrm{C}$.

Cardemil et al. (Miguel Cardemil et al. 2016) compared adding solar heat at two locations in single- and double-flash plants in the Atacama Desert, Chile. After the flash tank, the solar field could either superheat the steam or evaporate the brine. Using second-law analysis, it was concluded that superheating the steam was slightly more efficient because the turbine operated more efficiently with dry steam. Double-flash systems were also found to be preferable to singleflash plants.

In previous research (published as a conference paper (McTigue et al. 2017)), solar heat was added to a fraction of the injection brine, which was recirculated and mixed with the production fluids rather than being injected. This report uses improved models of the geothermal field and steam turbine so several alternative configurations are investigated. Five configurations were considered and are illustrated in Figure 4a. These five options are:

1. Heat a fraction of the injection brine until it reaches saturation temperature (INJ)

2. Heat a fraction of the injection brine until it has a vapor fraction of 0.50 (INJ2)

3. Heat a fraction of the condensed water from the condenser until it is saturated vapor (COND)

4. Heat the production fluids, thereby increasing their vapor fraction (PRE)

5. Heat a fraction of the unflashed brine that leaves the first flash tank (FT1).

The impact of adding solar heat $Q_{\text {sol }}$ at these different locations is presented in Figure 4b-e. These figures indicate that $Q_{\text {sol }}$ increases power output and first-law efficiency $\eta 1$, while the solar-conversion efficiency $\eta_{\text {sol }}$ is approximately constant. Increasing $Q_{\text {sol }}$ increases the steam flow rate that is delivered to the HP turbine. As a result, the inlet pressure increases in order to pass the same volumetric flow. However, the geothermal well also has a characteristic curve: 
Mass flow rate is inversely related to pressure (Dipippo 2016). Increasing the turbine inlet pressure therefore requires a lower mass flow rate from the geothermal field, thereby potentially increasing the lifetime of the geothermal resource.

The turbine inlet pressure is constrained to $1.1 \mathrm{x}$ the design value. Beyond this pressure, the HP turbine is throttled, and its inlet conditions are kept constant. More mass consequently enters the LP stage, although this has a reduced smaller influence on the overall system performance. The power increases at a slower rate, but $\eta_{\text {sol }}$ drops significantly, as does $\eta 1$. 

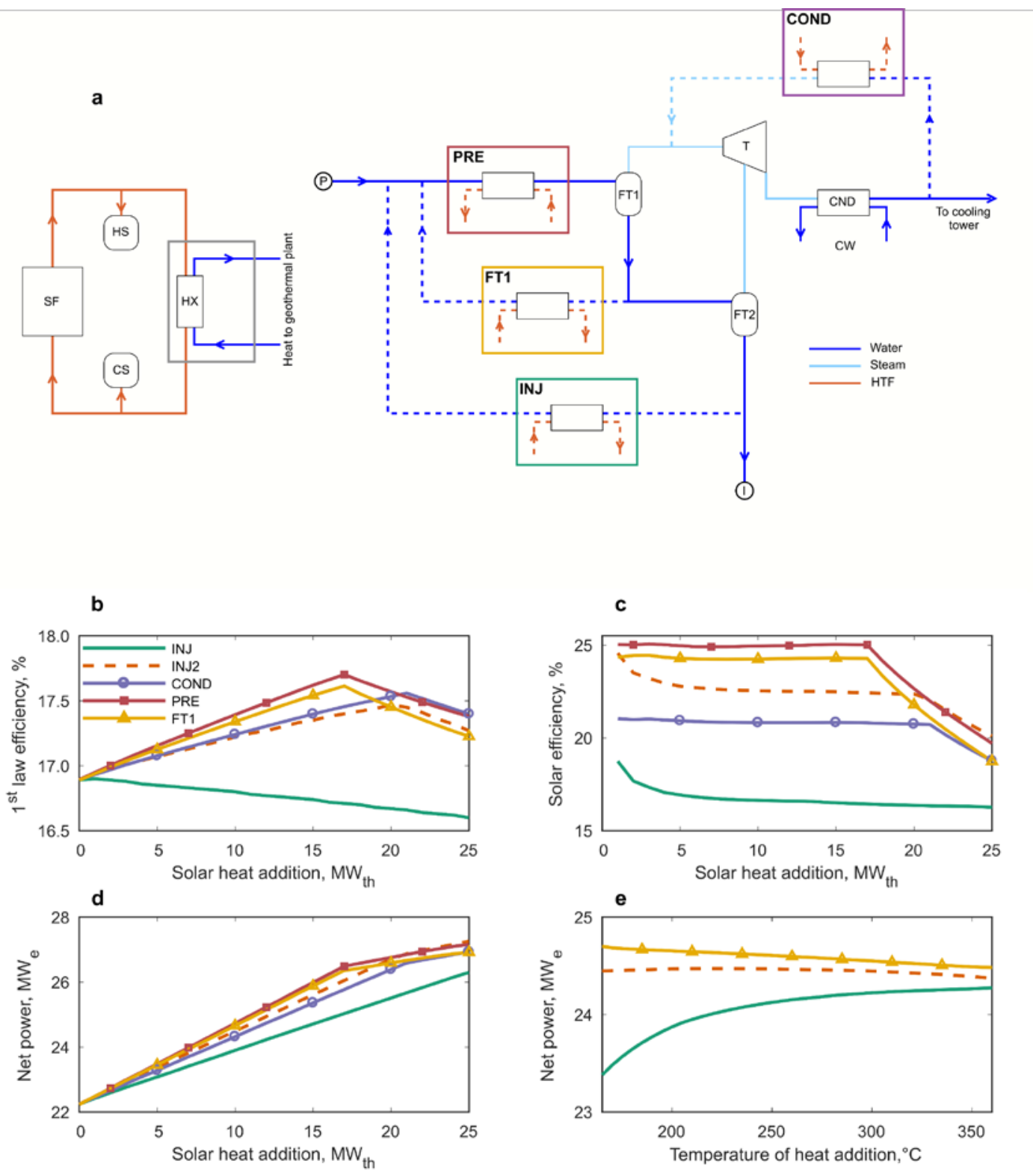

Figure 4. Solar heat can be added at different points in the geothermal power plant

a, Schematic of hybrid power plant with solar heat added at four locations: INJ - injection brine is heated to saturation temperature; INJ2 - same as INJ, except fluid is heated until the vapor fraction is $50 \%$; COND - the condensed water is heated; PRE - geothermal production fluids are preheated; FT1 - brine at the first flash tank exit is heated. $\mathbf{b}$, Variation of first-law thermal efficiency with the quantity of solar heat addition. c, Variation of solar-conversion efficiency with the quantity of solar heat addition. $\mathbf{d}$, Variation of net power with quantity of solar heat addition. $\mathbf{e}$, Variation of net power with the temperature of solar heat addition. Key: SF - solar field; HS - hot store; CS - cold store; HX - heat exchanger; P production well; I - injection well; FT1 - flash tank 1; FT2 - flash tank 2; T - turbine; CND - condenser; $\mathrm{CW}$ - cooling water. Valves, pumps, etc. are not shown for clarity. In $\mathbf{b}, \mathbf{c}$, and $\mathbf{d}$, the solar field HTF is heated to $225^{\circ} \mathrm{C}$. The HTF cold temperature is set to be $25^{\circ} \mathrm{C}$ greater than the geothermal inlet fluid.

The relative merits of each configuration are now described. 
INJ: Unflashed brine is pressurized to 15 bar and re-injected into the ground at $\sim 104^{\circ} \mathrm{C}$. A fraction of this brine is heated by the solar field until becoming saturated liquid and is then mixed with the production fluids. This configuration shows the poorest performance with the power input increasing $0.16 \mathrm{MW}_{\text {e }}$ per $\mathrm{MW}$ th heat addition. The first-law efficiency $\eta_{1}$ decreases as solar heat is added because the solar-conversion efficiency $\eta_{\text {sol }}$ is less than the first-law efficiency when $Q_{\text {sol }}=0$ (see Appendix B). Increasing the re-heat brine temperature improves performance slightly by increasing the specific enthalpy of the mixed fluid.

INJ2: Allowing the injection brine to evaporate (to a vapor fraction of 50\%) improves the performance compared to INJ. The solar addition efficiency increases to $22.5 \%$ from around $17 \%$, and $\eta_{1}$ increases with heat addition. However, this approach may result in increased scaling of pipes and heat exchanger. Using a shell-and-tube heat exchanger with the brine inside the tubes will make it easier to clean, although phase change normally occurs on the shell-side.

COND: Water leaves the condenser at $\sim 38^{\circ} \mathrm{C}$ and 0.1 bar and can be evaporated without scaling. Saturated vapor is injected directly into the HP turbine stage, and its temperature is set by the turbine inlet pressure. In some implementations, such as direct steam production in the solar field, this approach requires space near the power block for the solar field, otherwise large pressure losses will arise from pumping saturated vapor long distances. A similar scheme involves heating the turbine exhaust steam, which would increase the mass added to the system for the same heat addition because the exhaust is hotter $\left(\sim 46^{\circ} \mathrm{C}\right)$ than the condenser water. However, the exhaust is an LP (0.1 bar) two-phase mixture, and pumping this fluid to the required pressure (6 bar) would take a considerable work input and a two-phase pump. Furthermore, an isentropic compression would increase the fluid temperature to $550^{\circ} \mathrm{C}$, thereby rendering the solar field redundant.

PRE: The two-phase production fluids are heated, thereby increasing their vapor fraction. This method sees the highest increase in power output per unit heat addition, with $\eta_{\text {sol }}=25 \%$. Evaporation can lead to an increased rate of scaling (Nakao et al. 2017), although the precipitations could be delayed by the introduction of $\mathrm{H}_{2} \mathrm{SO}_{4}$. A larger heat exchanger may also be required due to the larger flow rates and generation of steam. For instance, $Q_{\text {sol }}=10 \mathrm{MW}_{\text {th }}$ heats $110.6 \mathrm{~kg} \mathrm{~s}^{-1}$ of production fluids compared to $24.6 \mathrm{~kg} \mathrm{~s}^{-1}$ for INJ and $62.0 \mathrm{~kg} \mathrm{~s}^{-1}$ for FT1.

FT1: Brine leaves the first flash tank (FT1) at $\sim 160^{\circ} \mathrm{C}$ compared to the FT2 outlet, which is $104^{\circ} \mathrm{C}$. Heating FT1 brine therefore recirculates more mass per unit heat addition. This approach has a comparable performance to PRE, with $\eta_{\text {sol }}=24.3 \%$. Increasing the temperature that the fluid is heated to reduces net power by a small quantity - the increase in enthalpy of the mixed fluid is outweighed by the increased pumping power. This configuration has the best performance with the least risk of scaling and is investigated further below. 


\section{Economic Analysis}

\subsection{Cost Correlations}

Cost correlations for each additional component in the hybrid plant were derived from several sources.

Heat transfer fluids: Quotes were obtained for bulk quantities of HTFs from several suppliers, and values are provided in Appendix A. In this case, bulk quantities are over 5,000 gallons (19 $\mathrm{m}^{3}$ ). These estimates do not include the cost of shipping. Two HTFs are considered in this report: a mineral oil (Xceltherm 600) with a cost of $\$ 2.5 / \mathrm{kg}$ and a synthetic fluid (Therminol VP1) with a cost of $\$ 3.1 / \mathrm{kg}$.

Pressure vessel: The pressure vessel contains the storage media. Numerous correlations are available for storage vessel costs. Several pressure vessel cost estimates were obtained from PCL Construction Ltd. by Coso Operating Company. These quotes fit well with a correlation derived from Peters and Timmerhaus (Peters and Timmerhaus 1990) (when costs were inflated to current values) for unpressurized vessels. The cost of the vessel depends on its volume $V$ and is given by:

$C_{\text {ves }}=7351 V^{0.557}$

Pressurizing the store significantly increases the cost, and the following correlation was obtained from EconExpert:

$C_{\text {pres }}=0.922+0.0335 P-0.0003 P^{2}+1 \times 10^{-6} P^{3}$

The total cost of the pressure vessel is therefore given by $C_{\mathrm{PV}}=C_{\text {pres }} C_{\text {ves }}$.

Heat exchanger: Correlations were obtained from EconExpert for a floating-head, shell-and-tube heat exchanger constructed from carbon steel.

$C_{\mathrm{HX}}=\beta\left(18944.44+280.71 A-0.06601 A^{2}\right)$

$\beta=1$ for $P<10$ bar

$\beta=1.0011+0.001 P$ for $P \geq 10$ bar

Where $P$ is the pressure, and $A$ is the heat transfer area. $A$ is calculated using the log-mean temperature difference method, where

$$
A=\frac{Q}{U \cdot \text { LMTD }}
$$

Where $Q$ is the heat transferred, $U$ is the overall heat transfer coefficient (assumed to have a constant value of $1,000 \mathrm{~W} / \mathrm{m}^{2} \mathrm{~K}$ ), and LMTD is the log-mean temperature difference, given by 
$\operatorname{LMTD}=\frac{\Delta T_{h}-\Delta T_{c}}{\log \left(\Delta T_{h}\right)-\log \left(\Delta T_{c}\right)}$

Where $\Delta T_{\mathrm{h}}$ is the temperature difference on the hot side of the heat exchanger, and $\Delta T_{\mathrm{c}}$ is the temperature difference on the cold side of the heat exchanger.

Pump:

$C_{\text {pump }}=5648.8 P^{0.4305} \dot{W}^{0.4121}$

This expression was derived from EconExpert for a centrifugal pump made from cast steel. $P$ is the discharge pressure, and $W$ is the rated power.

Solar field: The solar field is assumed to be in the range of $\$ 100-200 / \mathrm{m}^{2}$ following discussions with Hyperlight Energy.

Price of electricity: The price of electricity was set at $\$ 0.09 / \mathrm{kWh}$ following discussions with industrial partners.

Sensitivity analysis: The cost of each component was assumed to follow a normal distribution $C \sim N\left(\mu, \sigma^{2}\right)$, which was truncated to prevent negative costs. A Monte Carlo simulation with 10,000 runs was undertaken. For each run, each component normal distribution was sampled and the economic metrics evaluated to develop a distribution of costs. The mean value of each distribution was that given by the equations above. The value of each standard deviation is given in Table 5.

Table 5. Parameters Used in Sensitivity Analysis

\begin{tabular}{llllll} 
& & Mean value $\mu, \$$ & Standard deviation & Upper limit & Lower limit \\
\hline Solar field & $\$ / \mathrm{m}^{2}$ & 150 & $0.20 \mu$ & $10 \mu$ & $0.30 \mu$ \\
HTF & $\$$ & - & $0.10 \mu$ & $5.0 \mu$ & $0.30 \mu$ \\
Pressure vessel & $\$$ & - & $0.25 \mu$ & $20 \mu$ & $0.30 \mu$ \\
Heat exchanger & $\$$ & - & $0.20 \mu$ & $10 \mu$ & $0.30 \mu$ \\
Pump & $\$$ & - & $0.20 \mu$ & $10 \mu$ & $0.30 \mu$ \\
Electricity price & $\$ / \mathrm{kWh}_{\mathrm{e}}$ & 0.09 & $0.20 \mu$ & $1.50 \mu$ & $0.20 \mu$
\end{tabular}

Dash indicates costs are calculated from correlations above.

\subsection{Levelized Cost of Electricity and Internal Rate of Return}

The levelized cost of electricity (LCOE) is the cost that, if assigned to every unit of electrical energy produced over the lifetime of the plant, will equal the total life cycle costs when discounted back to the current year (Short and Packey 1995). The total life cycle costs include capital costs and O\&M costs. In the case of the hybrid plant where the power block and geothermal wells already exist, the annual electrical energy is given by the marginal increase in electrical energy above the base rate provided by the geothermal plant.

The LCOE is calculated using the fixed charge rate (FCR) method, where 
$\mathrm{LCOE}=\frac{C_{\text {cap }} \mathrm{FCR}+M}{E}$

Where $C_{\text {cap }}$ is the capital cost, $M$ is the annual O\&M costs, $E$ is the annual electricity generation, and FCR is the fixed charge rate. FCR is defined as the revenue per unit of investment that must be collected annually to pay for the carrying charges of the investment. Details of how to calculate the FCR may be found in (Short and Packey 1995).

$\mathrm{FCR}=(\mathrm{PFF})(\mathrm{CRF})$

PFF is the project financing factor, and CRF is the capital recovery factor. PFF is given by

$\mathrm{PFF}=\frac{1-T(\mathrm{PVDEP})}{1-T}$

Where $T$ is the tax rate (40\%) and PVDEP is the present value of depreciation, which is given by $\operatorname{PVDEP}=\sum_{j=0}^{N} \frac{D_{j}}{(1+\mathrm{WACC})(1+i)^{j}}$

Where $D_{j}$ is the depreciation rate in year $j$. In this case, depreciation occurs for the first five years at rates of $20 \%, 32 \%, 20 \%, 14 \%$, and $14 \%$ and at $0 \%$ thereafter. $i$ is the inflation rate (2.5\%), and WACC is the weighted average cost of capital, given by

$$
\text { WACC }=\frac{1+(1-d)((1+\mathrm{RROE})(1+i)-1)+d(1-T)((1+\mathrm{RINT})(1+i)-1)}{1+i}-1
$$

Where $d$ is the project debt fraction (50\%), RROE is the real return on investment, given by

$$
\mathrm{RROE}=\frac{1+\mathrm{IRR}}{1+i}-1
$$

Where IRR is the internal rate of return, given by $10 \%$. RINT is the real debt interest rate, given by

$$
\mathrm{RINT}=\frac{1+\mathrm{NINT}}{1+i}-1
$$

Where NINT is the nominal debt interest rate, which is assumed to be $8 \%$.

The CRF is given by

$$
\mathrm{CRF}=\frac{\text { WACC }}{\left(1-\frac{1}{1+\text { WACC }}\right)^{N}}
$$


Where $N$ is the lifetime of the plant in years, which is assumed to be 30 years. Assumed values for each of the economic parameters are given in Table 6 and are derived from the default values in the System Advisor Model (SAM).

Internal rate of return

The internal rate of return (IRR) of an investment that has a series of future cash flows $F_{i}$ is the rate of return that sets the net present value (NPV) of the cash flows equal to zero.

$\sum_{i=0}^{N} \frac{F_{i}}{(1+\mathrm{IRR})^{i}}=\mathrm{NPV}=0$

Where the cash flow $\mathrm{F}$ in year $\mathrm{i}$ is given by

$F_{i}=R_{i}-I_{i}-M_{i}-\left(R_{i}-D_{i}-M_{i}\right) T$

Where $\mathrm{R}$ is the revenue, $\mathrm{I}$ is the investment, $\mathrm{M}$ is the O\&M costs, $\mathrm{D}$ is the depreciation, and $\mathrm{T}$ is the tax rate. For the hybrid plant, the revenue is the marginal revenue above that which would have been produced by the geothermal power plant.

Note that the equation for IRR is a Laguerre polynomial with $\mathrm{N}$ roots. For the case of an initial cash investment followed by cash inflows, there is only one positive root, and the remainder are negative or imaginary.

Table 6. Economic Factors Used in LCOE Calculations

\begin{tabular}{ll} 
Economic parameters & Assumed values \\
\hline Tax rate, $T, \%$ & 40 \\
Inflation rate, $i, \%$ & 2.5 \\
Project debt fraction, $d, \%$ & 60 \\
Internal rate of return, IRR, \% & 10 \\
Nominal debt interest rate, NINT, \% & 8 \\
Depreciation rate, $D_{j}, \%$ & $20,32,20,14,14 ; 0$ thereafter
\end{tabular}




\section{Optimal Plant Sizing}

\subsection{Levelized Cost of Electricity}

Variations in available solar resource affect the hybrid plant performance. The thermal power delivered by the solar collector is a function of the sun angle, the direct normal irradiance (DNI), the mirror properties, and the HTF temperature. The temperature difference between the two liquid tanks containing HTF forms the thermal storage and such stores have been used in several CSP installations previously.

In the light of the above results, configuration FT1 is investigated further with economic metrics. The design point of the hybrid plant has been selected as a 2-MWe increase in electricity generation. The power output increases from 22.2 $\mathrm{MW}_{\mathrm{e}}$ for the standalone geothermal plant to 24.2 $\mathrm{MW}_{\mathrm{e}}$ for the hybrid plant. This corresponds to a thermal power of $8 \mathrm{MW}_{\text {th }}$ for the FT1 design. Generating this thermal power requires a solar field with a primary mirror area of 14,159 $\mathrm{m}^{2}$ (3.5 acres) at the peak DNI on the summer solstice $\left(973 \mathrm{~W} \mathrm{~m}^{-2}\right)$. A solar field of this size has a solar multiple of $\sigma=1$. Increasing the solar multiple proportionally increases the solar field size and its power output. The storage strategy is to store energy when the collector power exceeds $8 \mathrm{MW}_{\text {th }}$ and to discharge when it is less than $8 \mathrm{MW}_{\text {th. }}$

The operating point of the geothermal system with $8 \mathrm{MW}$ th power addition is shown in Table 7. If the solar collectors provide more than $8 \mathrm{MW}$ th, then the excess energy is stored. Once the thermal stores are full, the excess energy is dispatched to the geothermal plant, up to a maximum

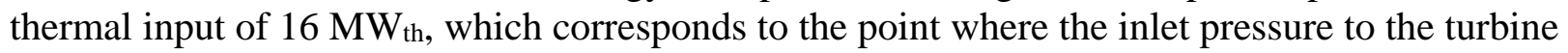
can no longer be increased and the turbine must be throttled. Beyond this heat input, thermal energy from the solar field is curtailed.

Table 7. Operating Point of Hybrid Plant Using FT1 Configuration

\begin{tabular}{lrcc} 
& & HP stage & LP stage \\
\hline Temperature & ${ }^{\circ} \mathrm{C}$ & 162.6 & 100.0 \\
Pressure & $\mathrm{bar}$ & 6.10 & 1.01 \\
Mass flow rate & $\mathrm{kg} / \mathrm{s}$ & 47.2 & 54.2 \\
\hline Recirculated temperature & ${ }^{\circ} \mathrm{C}$ & \multicolumn{2}{c}{162.6} \\
Recirculated pressure & $\mathrm{bar}$ & \multicolumn{2}{c}{6.60} \\
Recirculated mass flow rate & $\mathrm{kg} / \mathrm{s}$ & \multicolumn{2}{c}{147.9} \\
Gross power & $\mathrm{MWe}$ & \multicolumn{2}{c}{24.5} \\
Net power & $\mathrm{MW}$ & \multicolumn{2}{c}{24.2} \\
Efficiency & $\%$ & \multicolumn{2}{c}{17.3} \\
Solar conversion efficiency & $\%$ & \multicolumn{2}{c}{24.3}
\end{tabular}

The hourly behavior of the hybrid system is illustrated in Figure 5 for $\sigma=2$ and 4 . Graphs are shown at the summer and winter solstice to show the extreme cases. At $\sigma=2$, the plant cannot deliver the target thermal power ( $8 \mathrm{MW}$ th) in the winter solstice and stores are underutilized, discharging only $0.1 \%$ of the energy that they potentially could (see Table 8 ). Solar multiples of 4 are high compared to most installations. However, the stores are still used to only a small extent throughout the winter, with utilizations of $25 \%$ for an 8-hour store (see Table 8). On the other hand, during the summer the stores are fully charged on a daily basis with utilizations over 99\%. This leads to power being curtailed, as can be seen in Figure 5b, which indicates that the 
solar field is not cost efficient. This indicates that there is an inherent trade-off in sizing the solar field and thermal stores: Large solar fields are required to provide the necessary power in the winter. However, this leads to an oversupply of energy in the summer, which requires large stores to avoid curtailment. These large stores are then severely underutilized in the winter.
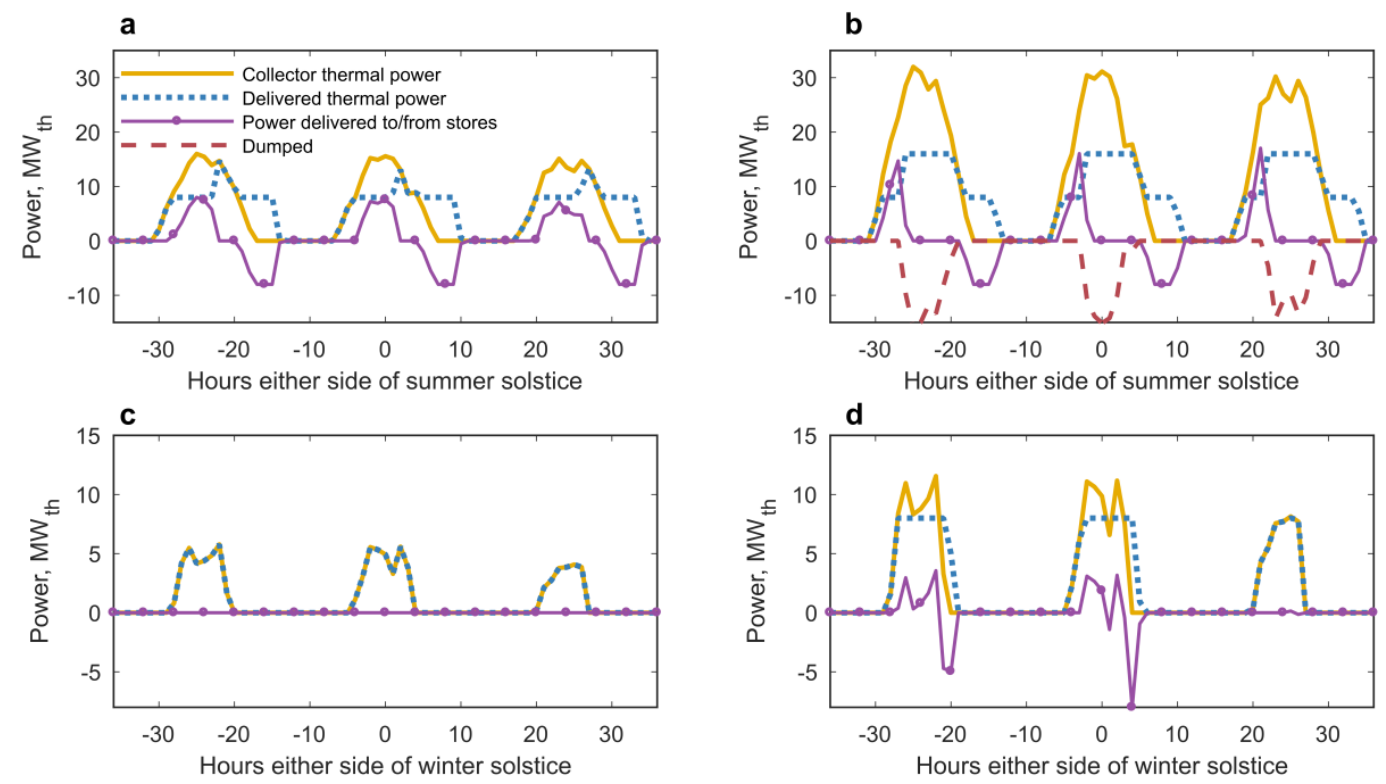

Figure 5. Power flows in the hybrid power plant for the summer solstice and winter solstice

a, Summer solstice, solar multiple $=2$. b, Summer solstice, solar multiple $=4$. $\mathbf{c}$, Winter solstice, solar multiple $=2$. $\mathbf{d}$, Winter solstice, solar multiple $=4$.

Table 8. Performance of Stores in the Hybrid Plant

\begin{tabular}{|c|c|c|c|c|c|}
\hline & & \multicolumn{2}{|c|}{ Solar multiple $=2$} & \multicolumn{2}{|c|}{ Solar multiple $=4$} \\
\hline Solar field mirror area & $\mathrm{m}^{2}$ & & 28,318 & & 56,636 \\
\hline Total collector energy & $\mathrm{GWh}_{\text {th }}$ & & 28.83 & & 57.66 \\
\hline Total increase in electrical energy & $\mathrm{GWh}_{\mathrm{e}}$ & & 6.97 & & 11.37 \\
\hline Average electricity generated ${ }^{a}$ & $\mathrm{MWh}_{\mathrm{e}}$ & & 23.0 & & 23.5 \\
\hline Average first-law efficiency & $\%$ & & 17.7 & & 18.5 \\
\hline \multirow[t]{3}{*}{ Capacity factor b } & $\%$ & & 42.0 & & 67.6 \\
\hline & & \multicolumn{2}{|c|}{ Storage } & \multicolumn{2}{|c|}{ Storage } \\
\hline & & $4 \mathrm{~h}$ & $8 \mathrm{~h}$ & $4 \mathrm{~h}$ & $8 \mathrm{~h}$ \\
\hline Total energy discharged & $\mathrm{GWh}_{\text {th }}$ & 6.1 & 7.0 & 9.7 & 17.4 \\
\hline Utilization ${ }^{\mathrm{c}}$ & $\%$ & 52.4 & 30.0 & 83.2 & 74.6 \\
\hline Average energy discharged (May-Jul) & $M W h_{\text {th }} /$ day & 30.0 & 37.7 & 31.8 & 63.4 \\
\hline Utilization (May-Jul) & $\%$ & 93.4 & 59.0 & 99.3 & 99.0 \\
\hline Average energy discharged (Nov-Jan) & $\mathrm{MWh}_{\mathrm{th}} /$ day & 0.1 & 0.1 & 14.9 & 15.7 \\
\hline Utilization (Nov-Jan) & $\%$ & 0.2 & 0.1 & 46.5 & 24.6 \\
\hline Total energy curtailed & $\mathrm{GWh}_{\text {th }}$ & 0.0 & 0.0 & 10.7 & 6.7 \\
\hline
\end{tabular}

a The average electricity generated per day without solar is $22.2 \mathrm{MWe}$.

$\mathrm{b}$ The capacity factor is defined as the average additional electricity divided by the design value of additional electricity $\left(2 \mathrm{MW}_{\mathrm{e}}\right)$.

${ }^{c}$ The storage utilization is defined as the total energy discharged divided by the total energy that would have been dispatched if the store had been fully charged and discharged once per day. 
a

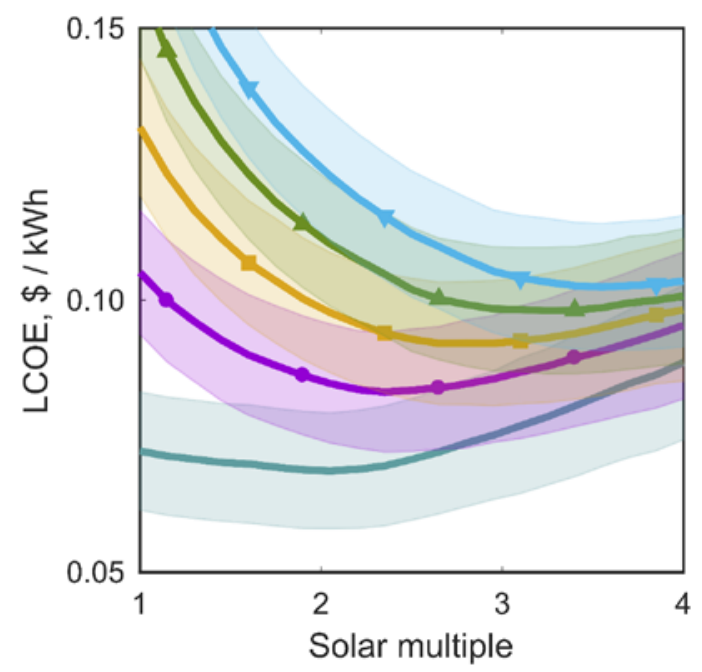

b

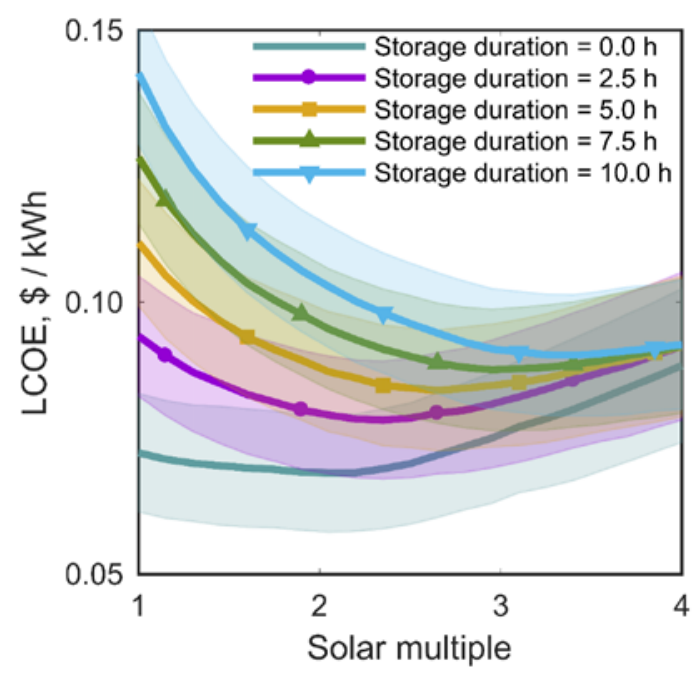

Figure 6. Effect of solar field size and thermal storage sizing on the levelized cost of energy

a, The hot thermal store is at $300^{\circ} \mathrm{C}$ with the Xceltherm 600 mineral oil for storage medium. $\mathbf{b}$, The hot thermal store is at $400^{\circ} \mathrm{C}$ with Therminol VP 1 as the storage medium. The shaded bands indicate the mean LCOE plus/minus one standard deviation. The cold store is $190^{\circ} \mathrm{C}$ in both cases.

The LCOE of the hybrid plant is calculated over a 30-year lifetime, as the size of the solar field, stores, and HTF temperature are varied. Figure 6 indicates that larger solar fields reduce the LCOE as more thermal power is delivered to the hybrid plant over the course of the year. However, very large solar multiples lead to an increase in LCOE due to curtailment of thermal energy. It is noticeable that at large solar multiples, the increase in LCOE with storage size is diminished. Rather than thermal energy being curtailed, the use of large thermal stores allows the total quantity of energy delivered to be increased.

Figure 6 and Table 9 compare the impact of using different HTFs as the storage media. Figure 6a illustrates the use of a mineral oil (Xceltherm 600$)$, which has low capital cost $(\$ 2.5 / \mathrm{kg})$, is nontoxic, and has low vapor pressures, so that the stores do not need to be pressurized. The mineral oil hot store temperature is $300^{\circ} \mathrm{C}$.

A synthetic fluid (Therminol VP-1) with a hot store temperature of $400^{\circ} \mathrm{C}$ is shown in Figure $6 \mathrm{~b}$. This synthetic fluid is a eutectic mixture of diphenyl and biphenyl oxides (DPO) (marketed as Dowtherm A, Therminol VP1, etc.). DPO has more expensive upfront costs $(\$ 3.1 / \mathrm{kg})$ compared to mineral oils. Furthermore, operating at higher temperatures increases the vapor pressure significantly ( $\sim 10$ bar at $393^{\circ} \mathrm{C}$ ), and pressurizing the stores increases their cost by a factor of $\sim 1.3$. Furthermore, DPO is more toxic and less environmentally friendly than mineral oils. Operators may be more cautious of storing large volumes of DPO (Denholm, Eichman, and Margolis 2017) after a fire at the SEGS1 CSP plant in 1999 (California Energy Commission 2010) destroyed $3,400 \mathrm{~m}^{3}$ (Associated Press 1999) of DPO and caused considerable damage. 
The cold tank in both cases has a temperature of $190^{\circ} \mathrm{C}$. Increasing the temperature difference between the stores increases the energy density, thereby reducing the storage volume and cost. Figure 6 indicates that this outweighs the impact of using a more expensive HTF and a pressurized vessel. For instance, the LCOE of a system with DPO, $\sigma=2$, and 4 hours of storage is $0.085 \pm 0.011 \$ / \mathrm{kWh}$ compared to an equivalent plant with mineral oil which costs $0.093 \pm$ $0.011 \$ / \mathrm{kWh}$. Using DPO instead of mineral oil reduces the storage capital cost from 60 to 39 $\$ / \mathrm{kWh}$. For instance, the DPO store capital cost per unit energy dispatched is nearly double $(114.5 \$ / \mathrm{kWh})$ the capital cost per unit capacity as a result of storage utilization of 52.5\%.

Note that the capital cost per unit energy can be calculated in two ways. Literature typically quotes the capital cost per unit energy capacity of the store. However, a more representative value is given by considering the extent to which the store is used-how much energy is discharged over a typical cycle. Table 9 provides the capital cost per unit energy dispatched, which is significantly larger than the capital cost per unit energy capacity.

Table 9. Costs and Sizes of Thermal Stores at Different Temperatures for 4 Hours of Storage

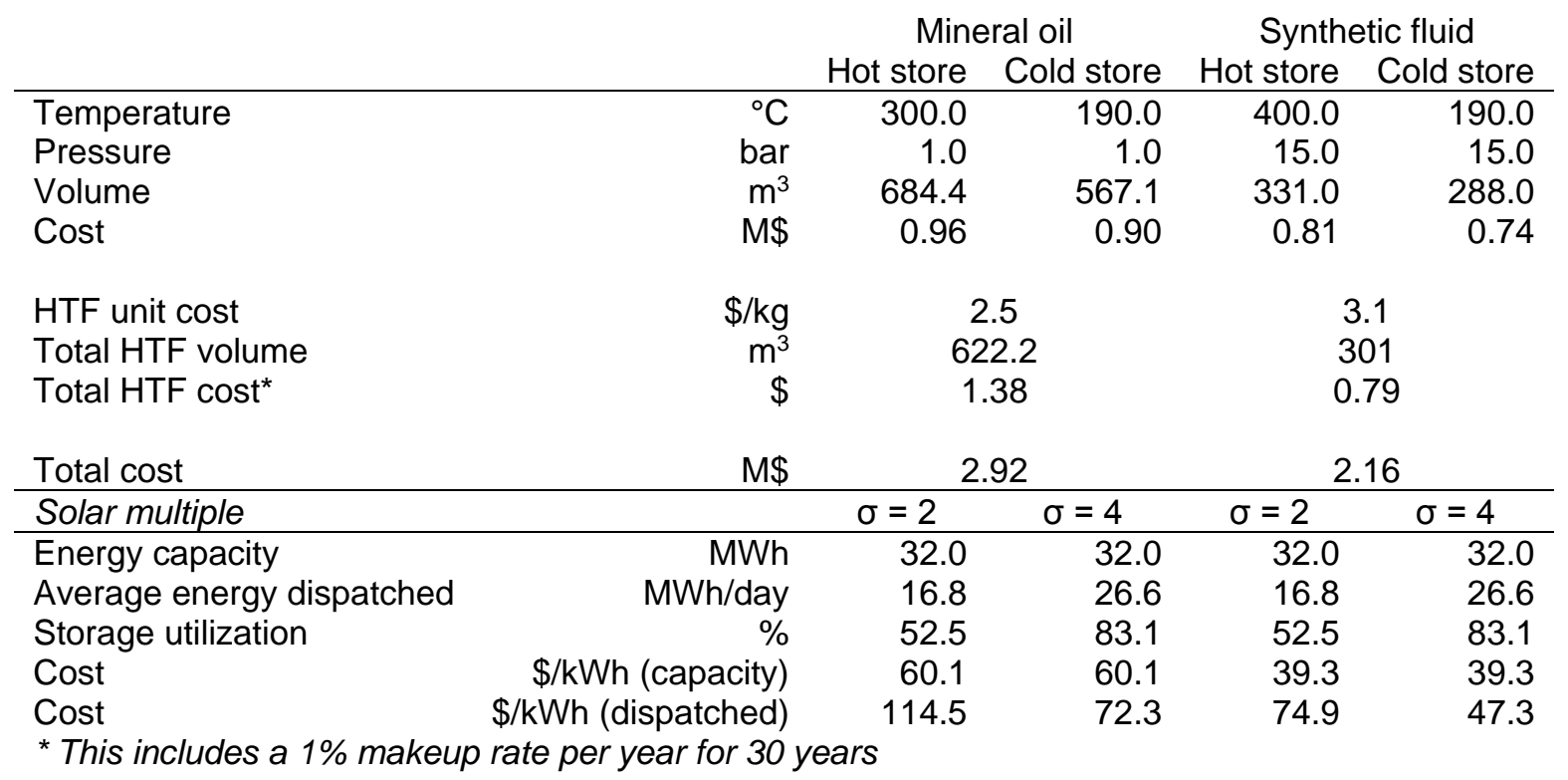

Larger thermal stores lead to higher LCOEs, as the total electricity generation remains roughly the same while the investment increases. The LCOE implies that the optimal storage size is zero and is therefore generally considered to be a flawed metric because it does not capture the value that storage provides to the plant or the grid (Denholm, Eichman, and Margolis 2017). Superior metrics exist, although there is little consensus among researchers about standardizing storage costs. A fundamental understanding of the behavior of the store and the value it provides can be obtained by considering the "utilization" of the store and the capital cost per unit energy dispatched. These metrics have been selected to illustrate how a storage size may be chosen, while attempting to minimize the number of economic assumptions that are made.

The storage utilization is the quantity of energy dispatched by the stores divided by the total energy that would have been dispatched if they were fully charged and discharged each day. Unsurprisingly, Figure 7a indicates that smaller stores have higher utilizations. Larger stores are 
rarely fully charged. The graph indicates that if small quantities of storage are required, it is better to have a solar field with a high solar multiple so that the stores are efficiently utilized.

Figure 7b shows the storage capital cost divided by the average energy dispatched from the store for the Therminol VP-1 storage system. Low storage durations have high capital costs, despite their high utilization. The capital cost increases at a decreasing rate with storage size as the storage hits economies of scale. As a result, the cost per kilowatt-hour decreases as the storage duration increases until an optimal point is reached. Beyond this, the reductions in utilization outweigh the economies of scale, and the cost per kilowatt-hour increases. As the solar multiple increases so does the optimal storage duration-larger solar fields have more energy available so that the utilization does not drop as rapidly, as illustrated in Figure 7a.

These graphs illustrate the inherent trade-off in sizing the thermal stores. Efficient use of the storage capacity requires small stores, but cost considerations indicate that larger stores are more cost-effective (from a storage perspective). Table 10 compares the economic cost of two solar field sizes with no storage and with the optimal duration of storage, according to the cost per kilowatt-hour dispatched for the Therminol VP-1 stores.
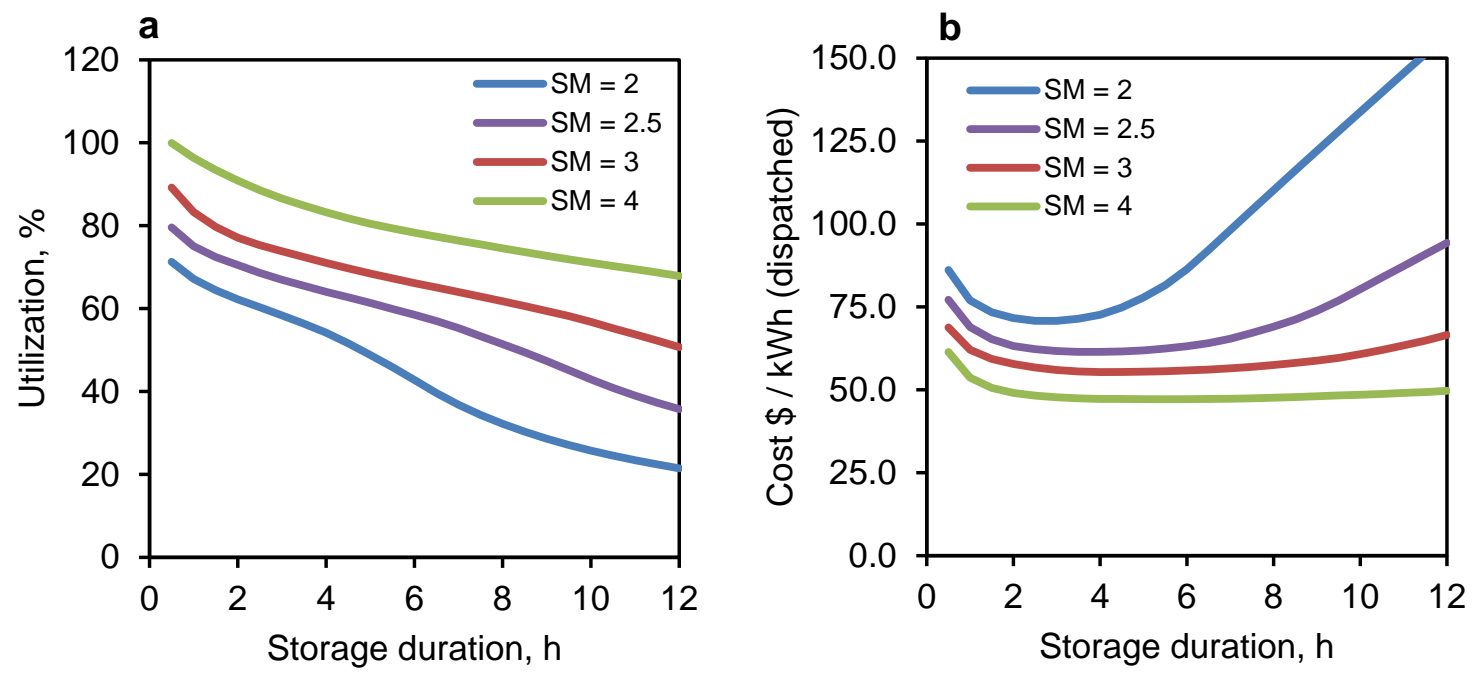

Figure 7. Utilization and cost per unit energy dispatched of thermal storage 
Table 10. Hybrid Plant Economics for Different Solar Multiples, With and Without Optimally Sized Stores

\begin{tabular}{|c|c|c|c|c|c|}
\hline & & \multicolumn{2}{|c|}{ Solar multiple $=2$} & \multicolumn{2}{|c|}{ Solar multiple = 3} \\
\hline & & $0 \mathrm{~h}$ (mineral) & $3 \mathrm{~h}$ (synthetic) & $0 \mathrm{~h}$ (mineral) & $10 \mathrm{~h}$ (synthetic) \\
\hline Total energy & $\mathrm{GWh}_{\text {th }}$ & 28.8 & 28.8 & 43.2 & 43.2 \\
\hline Additional electricity & $\mathrm{GWh}_{\mathrm{e}}$ & 6.98 & 6.97 & 9.34 & 10.42 \\
\hline Solar field cost & $\mathrm{M} \$$ & 4.25 & 4.25 & 6.37 & 6.37 \\
\hline Solar field HTF & $M \$$ & 0.230 & 0.286 & 0.345 & 0.430 \\
\hline Pump cost & $M \$$ & 0.211 & 0.211 & 0.211 & 0.211 \\
\hline $\mathrm{HX}$ cost & $\mathrm{M} \$$ & 0.060 & 0.046 & 0.060 & 0.046 \\
\hline HTF cost & $M \$$ & 0.0 & 0.595 & 0.0 & 1.982 \\
\hline Storage cost & $\mathrm{M} \$$ & 0.0 & 0.397 & 0.0 & 0.777 \\
\hline Capital cost & $\mathrm{M} \$$ & 4.750 & 5.785 & 6.986 & 9.816 \\
\hline Storage cost & $\$ / \mathrm{kWh}$ & 0.0 & 41.3 & 0.0 & 34.5 \\
\hline Storage utilization & $\%$ & 0.0 & 57.0 & 0.0 & 57.9 \\
\hline LCOE & $\$ / \mathrm{kWh}$ & $0.069 \pm 0.011$ & $0.081 \pm 0.011$ & $0.076 \pm 0.012$ & $0.091 \pm 0.011$ \\
\hline IRR & $\%$ & $7.73 \pm 3.24$ & $5.72 \pm 2.57$ & $6.58 \pm 3.05$ & $4.55 \pm 2.34$ \\
\hline
\end{tabular}

\subsection{Comparison with PV + Storage}

In this section, the economic feasibility of the hybrid plant is compared to a solar PV field with battery energy storage (BES) included. There are several sources that provide estimates of the LCOE of a PV plant with storage, as summarized in Table 11. While these values provide a valuable benchmark, assumptions differ between each study, and a wide range of estimates are available. It is therefore challenging to compare these values to those derived in this report. Consequently, the LCOE of a PV+BES has been estimated using the System Advisor Model (SAM) with the same economic assumptions as for the hybrid plant analysis.

The PV cell capital costs are estimated from NREL's Annual Technology Baseline (NREL 2017). Storage costs are obtained from Lazard's Levelized Cost of Storage (Lazard 2017a) report and are for Lithium-ion (Li-ion) batteries operating in the "Peaker Replacement" market. Li-ion batteries have a lifetime of approximately 10 years (Lazard 2017a), but the LCOE analysis occurs over a 30-year period. It is assumed that the batteries are replaced at the $10^{\text {th }}$ and $20^{\text {th }}$ year of operation, and the total battery cost is discounted appropriately. The LCOE is calculated for two cases that are equivalent to the hybrid design operating with a solar multiple of 2 and 3 and are therefore comparable to the results in Table 10. 
Table 11. LCOE of Solar PV Plus Storage Taken from the Literature

\begin{tabular}{|c|c|c|c|}
\hline Source & & Estimate, $\$ / k W h$ & Notes \\
\hline Lazard & (Lazard 2017b) & 0.082 & $\begin{array}{l}10 \text { hours of storage. Batteries degrade at } \\
0.40 \% / y e a r \text { and roundtrip efficiency of } \\
90 \% .200 \mathrm{MW}_{\mathrm{e}} \mathrm{PV} \text { field. }\end{array}$ \\
\hline Feldman 2016 & $\begin{array}{l}\text { (Feldman et al. } \\
\text { 2016) }\end{array}$ & $\begin{array}{l}0.16 \pm 0.05 \\
0.175 \pm 0.05 \\
0.19 \pm 0.05\end{array}$ & $\begin{array}{l}\text { Battery has a } 15 \text {-year lifetime and 3, } 6 \text {, or } \\
9 \text { hours of storage. } 2015 \text { estimate. } 100 \\
\text { MWe system. }\end{array}$ \\
\hline Fu 2017 & (Fu et al. 2017) & $0.04-0.06$ & No storage. 100 MWe system. 2017 value. \\
\hline IRENA & (IRENA 2016) & 0.13 & No storage. 2015 value. \\
\hline $\begin{array}{l}\text { Annual Technology } \\
\text { Baseline }\end{array}$ & (NREL 2017) & $0.067-0.134$ & No storage. 100 MWe system. \\
\hline
\end{tabular}

Table 12. LCOE for Solar PV Plus Storage Estimated Using the System Advisor Model, Assuming a Lifetime of 30 Years

\begin{tabular}{|c|c|c|c|c|c|}
\hline & & & Low & Medium & High \\
\hline & PV capital cost & $\$ / \mathrm{kW}$ & 1,000 & 1,300 & 1,700 \\
\hline & Operations cost & $\$ / k W$ & 14 & 14 & 14 \\
\hline & Storage capital cost & $\$ / k W h$ & 290 & 350 & 425 \\
\hline \multicolumn{6}{|c|}{ Annual energy generation } \\
\hline \multirow{3}{*}{$6.98 \mathrm{GWh}_{\mathrm{e}}$} & LCOE - no storage & $\$ / k W h$ & 0.047 & 0.060 & 0.076 \\
\hline & LCOE - $3 \mathrm{~h}$ storage & $\$ / \mathrm{kWh}$ & 0.088 & 0.108 & 0.135 \\
\hline & LCOE - $10 \mathrm{~h}$ storage & $\$ / k W h$ & 0.181 & 0.221 & 0.272 \\
\hline \multirow{3}{*}{$9.34 \mathrm{GWh}_{\mathrm{e}}$} & LCOE - no storage & $\$ / k W h$ & 0.047 & 0.060 & 0.076 \\
\hline & LCOE - 3 h storage & $\$ / k W h$ & 0.074 & 0.092 & 0.116 \\
\hline & LCOE - $10 \mathrm{~h}$ storage & $\$ / \mathrm{kWh}$ & 0.137 & 0.168 & 0.207 \\
\hline
\end{tabular}

The storage discharges with a power of $2 \mathrm{MW}_{\mathrm{e}}$. The nominal PV power capacity is also $2 \mathrm{MW}_{\mathrm{e}}$ because the nominal design point of the hybrid plant increases the turbine power output by this quantity. However, PV plants have different operational performance than CSP systems. Therefore, the PV field is sized so that it produces the same quantity of energy over the year as the equivalent hybrid plant. As a result, the PV field that corresponds to a solar multiple of 2 has a rated power of $3.225 \mathrm{MW}$ e and generates $6.98 \mathrm{GWhe}$ over the course of a year (compare with Table 10). The PV field that corresponds to a hybrid plant with a solar multiple of 3 has a rated power of $4.82 \mathrm{MW}_{\mathrm{e}}$ and generates $9.34 \mathrm{GWh}$. It is assumed that all the power produced by the PV field can be absorbed by the grid. Thus, no power is curtailed.

The PV field was modeled using SAM. The PV panels are assumed to be 1-axis tracking, with total system losses of $14.1 \%$, an inverter efficiency of $96 \%$, and a DC-to-AC ratio of 1.2 (the default values in SAM). This analysis uses the same economic assumptions as the hybrid LCOE calculations (see Table 6), and therefore, the results are directly comparable.

The LCOE of the hybrid plant is lower than the PV-BES system. For instance, the hybrid plant with $\sigma=2$ and 3 hours of storage has an LCOE of $0.081 \pm 0.011 \$ / \mathrm{kWh}$, compared to the 
equivalent PV field value of $0.112 \pm 0.024 \$ / \mathrm{kWh}^{1}$. Similarly, the hybrid plant with $\sigma=3$ and 10 hours of storage has an LCOE of $0.091 \pm 0.01 \$ / \mathrm{kWh}$, compared to the equivalent PV field value of $0.172 \pm 0.035 \$ / \mathrm{kWh}$. Given the level of uncertainty, it is fair to assume that there is a compelling economic argument to consider hybrid plants as a competitor to PV systems with batteries. However, if storage is not installed, then the PV field has a slightly lower LCOE.

The quantity of storage was chosen to be "optimal” for the hybrid plant and is unlikely to be the best quantity for the PV field. For instance, the PV field is "better" at producing energy in the winter and at the start and end of the day. Therefore, the PV field can produce the same quantity of energy annually as the hybrid plant without having to increase the size of the field by the same proportion. As a result, the power production profile is less "peaky" and exceeds the threshold for storage to a smaller extent. The stores therefore have lower utilizations and are probably not at their optimal point.

Assuming a peak DNI of $973 \mathrm{~W} / \mathrm{m}^{2}$ and a typically solar-cell efficiency of $20 \%$, the area of the $\mathrm{PV}$ array can be calculated. The area of the 3.225-MWe array is $16,572 \mathrm{~m}^{2}$, and the area of the 4.82-MWe array is $24,769 \mathrm{~m}^{3}$. Compare this to the mirror area of the CSP plant, which generates

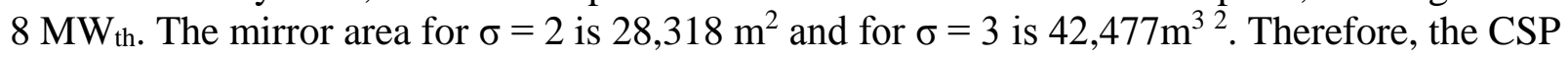
field requires 1.4 to 1.7 times as much space as the PV field.

It is worth noting that the concentrating solar field has been assumed to have relatively conservative cost and performance parameters. For instance, the cost of the solar field is 150 \$ / $\mathrm{m}^{2}$ which is higher than costs proposed by some manufacturers. Furthermore, linear Fresnel reflectors typically have poorer optical performance than parabolic trough technologies, and thereby produce less energy over the course of a year.

\subsection{Flexible Dispatch of Power}

The above analysis indicates that the lowest LCOEs are achieved without storage. However, storage increases the plant's flexibility as power can be dispatched during hours of greatest demand. Dispatchable power generation is increasingly important as renewable deployment increases. For instance, the deployment of 3,312 MWe (Fu et al. 2017) of utility PV on the California grid has led to a surplus of power during the afternoon. This results in the so-called “duck curve” (Denholm et al. 2015), whereby flexible power needs to be rapidly dispatched during the evening hours. It has also been suggested that the abundance of solar may lead to negative electricity prices. Consequently, other power generation units should be flexible, reducing power delivery during the afternoon and ramping at high slew rates during the evening. Combining baseload production (geothermal) with variable production (CSP) and thermal storage provides the flexibility to operate in such a marketplace. A hybrid system which includes dispatchable storage can provide other benefits to the grid, such as frequency control.

\footnotetext{
${ }^{1}$ Note, the PV+BES LCOE values are averages of those given in Table 12.

2 These areas are just for panels and mirrors and do not include spacing requirements.
} 
Since dispatchable power generation is a valuable it should be priced accordingly. This section investigates the price that stored energy should be dispatched at for the hybrid system to be economically viable.

The hybrid plant electricity is sold at a flat rate of $0.09 \$ / \mathrm{kWh}$. Electricity produced by discharging the stores is sold at a multiple of the flat rate, called a "price multiplier". For a system with a given storage duration and solar multiple, the price multiplier required for the system to have an internal rate of return of $10 \%$ is calculated. (This value of IRR represents a scenario where a system looks profitable). Results are presented in Figure 8. The curves indicate that there is an optimal storage size for each plant: as discussed above, small quantities of storage are expensive per $\mathrm{kWh}$ and therefore require high price multiples. Increasing the storage size increases the economic return, although extremely large stores are underutilized and again require high price multiples. For solar multiples of 2, the optimal storage size is around $3-4$ hours. Increasing the solar multiple increases the optimal storage duration to around 10 hours, as thermal energy availability has increased. Using a synthetic fluid typically requires lower price multipliers to achieve a profitable IRR than mineral oils, which is consistent with the above analysis. Profitable IRRs can be achieved with price multipliers in the region of $1.5-1.75$.

This analysis assumes that all dispatched energy from storage receives the increased price. As such it is not a reflection of the current electricity market where prices vary throughout the day and across the year. In such a scenario, large storage systems may be of little use, since higher prices may only be available for one or two hours of the day (and may coincide with times of high solar availability). Analyzing this scenario requires time of delivery pricing (including estimates for future years), as well as a control system for the optimal dispatch of storage. Rather than considering variable electricity pricing, we recognize that storage provides value to the grid in various ways that may not be directly quantifiable. Therefore, the 'price multipliers' reflect the average price that stored energy must be dispatched at for the system to be viable. 
a

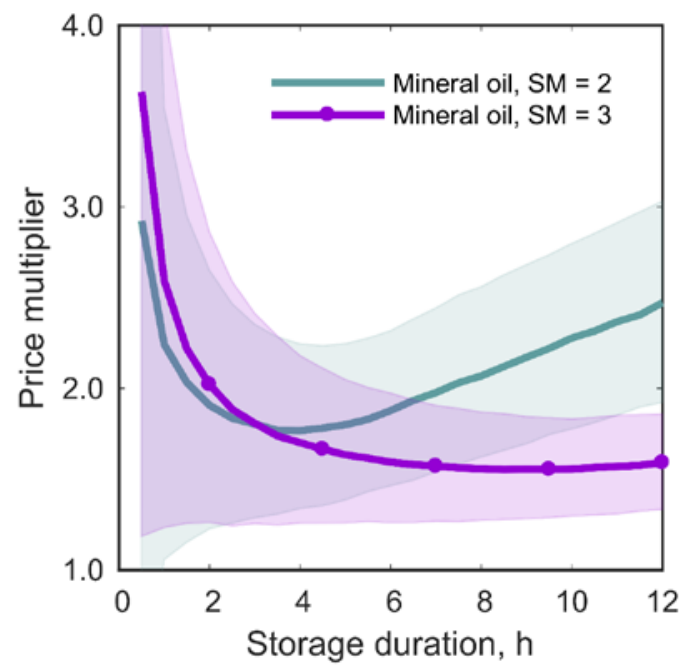

b

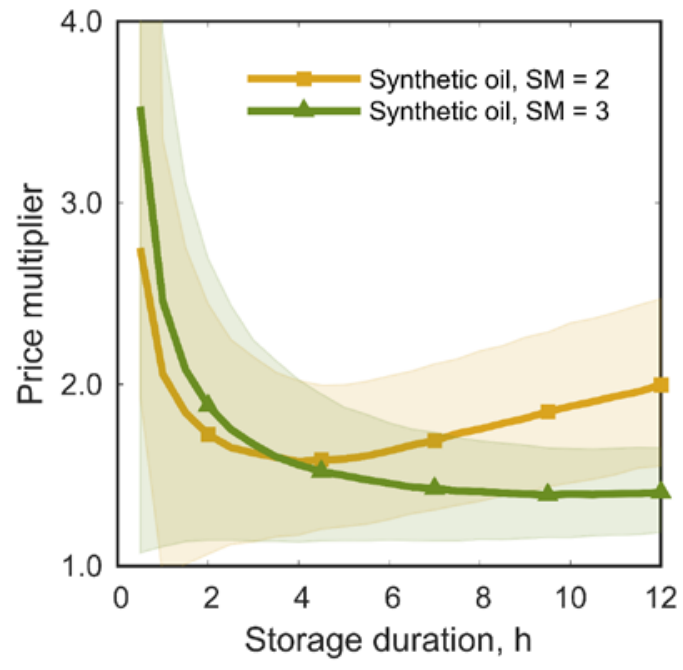

Figure 8. Curves showing the price multiplier required for a hybrid system with a given storage duration to achieve an internal rate of return of $10 \%$. The price multiplier is the increased price that stored energy is dispatched at. Shaded bands show the uncertainty.

a: Mineral oil storage, with the hot store at $300^{\circ} \mathrm{C}$. b: Synthetic oil storage, with the hot store at $400^{\circ} \mathrm{C}$. 


\section{Conclusions}

This report set out to develop a model of a hybrid geothermal-solar power plant and to investigate its performance. The economic feasibility of the hybrid plant was evaluated and compared to a solar PV plant with battery energy storage.

The main conclusions are summarized as:

- The thermodynamic performance of five different hybrid plant configurations were investigated.

- The configuration with the best performance and suitability involves reheating the unflashed brine at the exit of the first flash tank.

- An economic analysis of the hybrid plant was undertaken, and the LCOE was evaluated for plants with a range of thermal storage durations and solar field sizes.

- There is an optimal solar field size: Larger solar fields generate more power, but some of this power may have to be curtailed.

- The LCOE is not a suitable metric for evaluating systems with storage. Instead, the storage capital cost per unit energy discharged was used to determine the optimal storage size.

- Using a $400^{\circ} \mathrm{C}$ hot store with a synthetic fluid was found to be more cost-effective than using a $300^{\circ} \mathrm{C}$ hot store with a mineral oil, even though the synthetic fluid is more expensive and requires pressurized stores. However, the health and safety and environmental risks of the synthetic fluid need to be carefully considered.

- The LCOE of a hybrid plant with a solar multiple of 2 and a synthetic fluid storage duration of 3 hours is $0.081 \pm 0.011 \$ / \mathrm{kWh}$, while the LCOE of a comparably sized PV field with 3 hours of Li-ion battery storage is $0.112 \pm 0.024 \$ / \mathrm{kWh}$.

- Storage allows a power plant to dispatch power flexibly and provide value to the grid in several ways. If energy dispatched from the stores is valued at around 1.75 times the typical electricity price of $0.09 \$ / \mathrm{kWh}$ then the hybrid plant including four hours of storage has an internal rate of return of $10 \%$. 


\section{References}

Alvarenga, Y, S Handal, and M Recinos. 2008. "Solar Steam Booster in the Ahuachapan Geothermal Field.” Geothermal Resources Council 32nd Annual Meeting 32.

Associated Press. 1999. "Storage Tank at Solar Power Plant in Desert Explodes; Immediate Area Is Evacuated.” Los Angeles Times. Storage Tank at Solar Power Plant in Desert Explodes; Immediate Area Is Evacuated.

California Energy Commission. 2010. "Fire Department Response to Solar Thermal Power Plants.” https://goo.gl/aNmDLv.

Choo, Y K, and P J Staiger. 1982. "New Features and Applications of PRESTO , a Computer Code for the Performance of Regenerative , Superheated Steam Turbine Cycles.” In NASA TP 1954 c.1.

Cooke, D H. 1985. “On Prediction of Off-Design Multistage Turbine Pressures by Stodola's Ellipse 1.” Journal of Engineering for Gas Turbines and Power 107: 596-606.

Denholm, Paul, Matthew O Connell, Gregory Brinkman, and Jennie Jorgenson. 2015. "Overgeneration from Solar Energy in California : A Field Guide to the Duck Chart." Technical report NREL/TP-6A20-65023. http://www.nrel.gov/docs/fy16osti/65023.pdf.

Denholm, Paul, Josh Eichman, and Robert Margolis. 2017. "Evaluating the Technical and Economic Performance of PV Plus Storage Power Plants.” Technical report NREL/TP6A20-68737.

Denton, J D. 2017. “Loss Mechanisms in Turbomachines.” Journal of Turbomachinery 115 (October 1993).

Dipippo, Ronald. 2016. Geothermal Power Plants. 4th editio. Butterworth-Heinemann.

Dixon, Larry S, and Cesare A Hall. 2010. Fluid Mechanics and Thermodynamics of Turbomachinery. Elsevier Science.

Feldman, David, Robert Margolis, Joseph Stekli, David Feldman, Robert Margolis, and Joseph Stekli. 2016. "Exploring the Potential Competitiveness of Utility-Scale Photovoltaics plus Batteries with Concentrating Solar Power , 2015 - 2030.” NREL Technical Report TP6A20-66592.

Fu, Ran, David Feldman, Robert Margolis, Mike Woodhouse, and Kristen Ardani. 2017. "U.S. Solar Photovoltaic System Cost Benchmark : Q1 2017.” NREL Technical Report TP-6A2068925.

Fuller, L C, and T K Stovall. 1979. "A Computer Code for the Performance of Regenerative Superheated Steam-Turbine Cycles.” In ORNL-5547, NASA CR-159540.

Handal, S., Y Alvarenga, and M Recinos. 2007. “Geothermal Steam Production by Solar 


\section{Energy.” Geothermal Resources Council 31st Annual Meeting 31.}

IRENA. 2016. “The Power to Change: Solar and Wind Cost Reduction Potential to 2025.” Inernational Renewable Energy Agency.

Lazard. 2017a. “Lazard’s Levelized Cost of Storage Analysis - Version 3.0.”

—. 2017b. "Levelized Cost of Energy Analysis - Version 11.0.”

Mathur, Prem N. 1979. “An Assessment of Solar-Geothermal Hybrid System Concepts.”

McTigue, Joshua, Jose Castro, Greg Mungas, Nick Kramer, John King, and Craig Turchi. 2017. "Retrofitting a Geothermal Plant with Solar and Storage to Increase Power Generation." Transactions of the GRC 41.

Miguel Cardemil, José, Felipe Cortés, Andrés Díaz, and Rodrigo Escobar. 2016.

“Thermodynamic Evaluation of Solar-Geothermal Hybrid Power Plants in Northern Chile.” Energy Conversion and Management 123: 348-61. doi:10.1016/j.enconman.2016.06.032.

Nakao, Yoshinobu, Yoshihiro Mugikura, Kan Ogata, and Norito Katsuki. 2017. "Development of Hybrid Geothermal Power Plants in Japan.” In Transactions - Geothermal Resources Council. Vol. 41.

“National Solar Radiation Database.” 2017. Accessed November 12. https://nsrdb.nrel.gov/.

NREL. 2017. “2017 Annual Technology Baseline.” http://www.nrel.gov/analysis/data_tech_baseline.html.

Peters, M. S., and K. D. Timmerhaus. 1990. Plant Design and Economics for Chemical Engineers. McGraw-Hill, Inc.

Short, Walter, and Daniel J Packey. 1995. “A Manual for the Economic Evaluation of Energy Efficiency and Renewable Energy Technologies,” no. March.

Snyder, Diana M, Koenraad F Beckers, Katherine R Young, and Bud Johnston. 2017. “Analysis of Geothermal Reservoir and Well Operational Conditions Using Monthly Production Reports from Nevada and California” 41.

Spencer, R. C., K. C. Cotton, and C. N. Cannon. 1974. “A Method for Predicting the Performance of Steam Turbine-Generators 16,500 kW and Larger.”

Wendt, Daniel S, and Gregory L Mines. 2014. "Use of a Geothermal-Solar Retrofit Hybrid Power Plant to Mitigate Declines in Geothermal Resource Productivity” 38. 


\section{Appendix A}

Table A-1. Properties of the Heat Transfer Fluids Considered in this Report

\begin{tabular}{|c|c|c|c|c|c|c|c|c|c|c|}
\hline \multirow[b]{2}{*}{ HTF } & \multirow[b]{2}{*}{ Composition } & \multicolumn{2}{|c|}{ Temp., ${ }^{\circ} \mathrm{C}$} & Flash point, ${ }^{\circ} \mathrm{C}$ & \multirow[t]{2}{*}{$\begin{array}{l}\text { Fire point, } \\
{ }^{\circ} \mathrm{C}\end{array}$} & \multirow[t]{2}{*}{$\begin{array}{l}\text { Autoignition, } \\
{ }^{\circ} \mathrm{C}\end{array}$} & \multirow[t]{2}{*}{$\begin{array}{l}\text { Pour } \\
\text { point, }{ }^{\circ} \mathrm{C}\end{array}$} & \multirow[t]{2}{*}{$\begin{array}{l}\text { Boiling } \\
\text { point, }{ }^{\circ} \mathrm{C}\end{array}$} & \multicolumn{2}{|c|}{ Bulk cost ${ }^{3}$} \\
\hline & & Min. & Max. & $\begin{array}{l}\text { Open- } \\
\text { cup }\end{array}$ & & & & & $\$ / \mathrm{kg}$ & $\$ /\left(\mathrm{kJ} / \mathrm{m}^{3} \mathrm{~K}\right) \mathrm{kg}$ \\
\hline & Mineral and paraffir & & & & & & & & & \\
\hline Calflo AF & Paraffinic/mineral oil & & 316 & 221 & 240 & 343 & -42 & & 3.82 & 2.33 \\
\hline Calflo HTF & Paraffinic/mineral oil & & 326 & 231 & 245 & 352 & -18 & & 5.10 & 3.05 \\
\hline Calflo FG & Paraffinic/mineral oil & & 326 & 209 & 236 & 354 & -18 & & - & - \\
\hline Duratherm HTO & Paraffinic & & 315 & 207 & 223 & 360 & -15 & & 3.23 & 2.13 \\
\hline Duratherm 600 & Paraffinic & & 315 & 224 & 240 & 360 & -10 & & 4.42 & 2.77 \\
\hline Duratherm 630 & Paraffinic & & 332 & 229 & 244 & 368 & -18 & & - & - \\
\hline Duratherm HF & Paraffinic & & 338 & 276 & 305 & 393 & -9 & & - & - \\
\hline Marlotherm FG & Paraffinic/naphtenic & -7 & 300 & 190 & & 330 & -12 & $300-500$ & - & - \\
\hline Marlotherm LH & & -30 & 360 & 130 & & 510 & -30 & $278-282$ & - & - \\
\hline Marlotherm N & & -10 & 300 & 180 & & 330 & -60 & $330-400$ & - & - \\
\hline Marlotherm SH & & -5 & 350 & 200 & & 500 & -34 & $385-395$ & - & - \\
\hline
\end{tabular}

${ }^{3}$ The second bulk cost column shows the cost per volumetric heat capacity per kilogram at room temperature. This gives an indication as to the cost per energy storage capacity. 
Marlotherm XD

Multitherm OG 1 Mineral oil

Multitherm PG 1 Mineral oil

Multitherm $503 \quad$ Paraffinic

Hydrotreated heavy paraffinic

Paratherm HE distillate

Paratherm NF Hydrotreated mineral oil

\section{Petrotherm Paraffinic}

Xceltherm CA Hydrogenated white oil

Xceltherm $600 \quad$ Hydrogenated white oil

Therminol XP Mineral oil

\section{Synthetic fluids}

Dowtherm A Biphenyl and diphenyl oxide

Dowtherm G

Dowtherm Q

Dynalene SF

Paratherm HR

Paratherm HT
Di- and tri-aryl compounds

Diphenylethane and alkylated aromatics

Synthetic alkylated aromatics

Alkylated aromatic. Diisopropyl biphenyl

Hydrogenated Terphenyl
$-80$
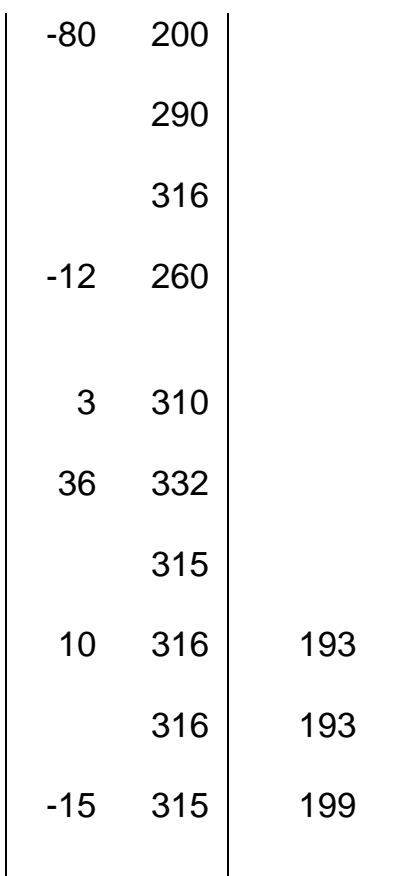
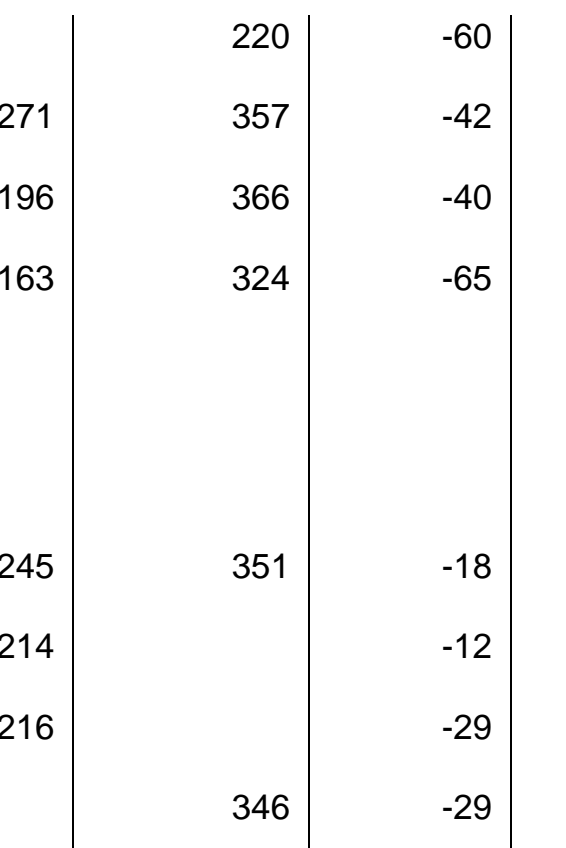

190-200

$373 \quad 6.60$

3.96 


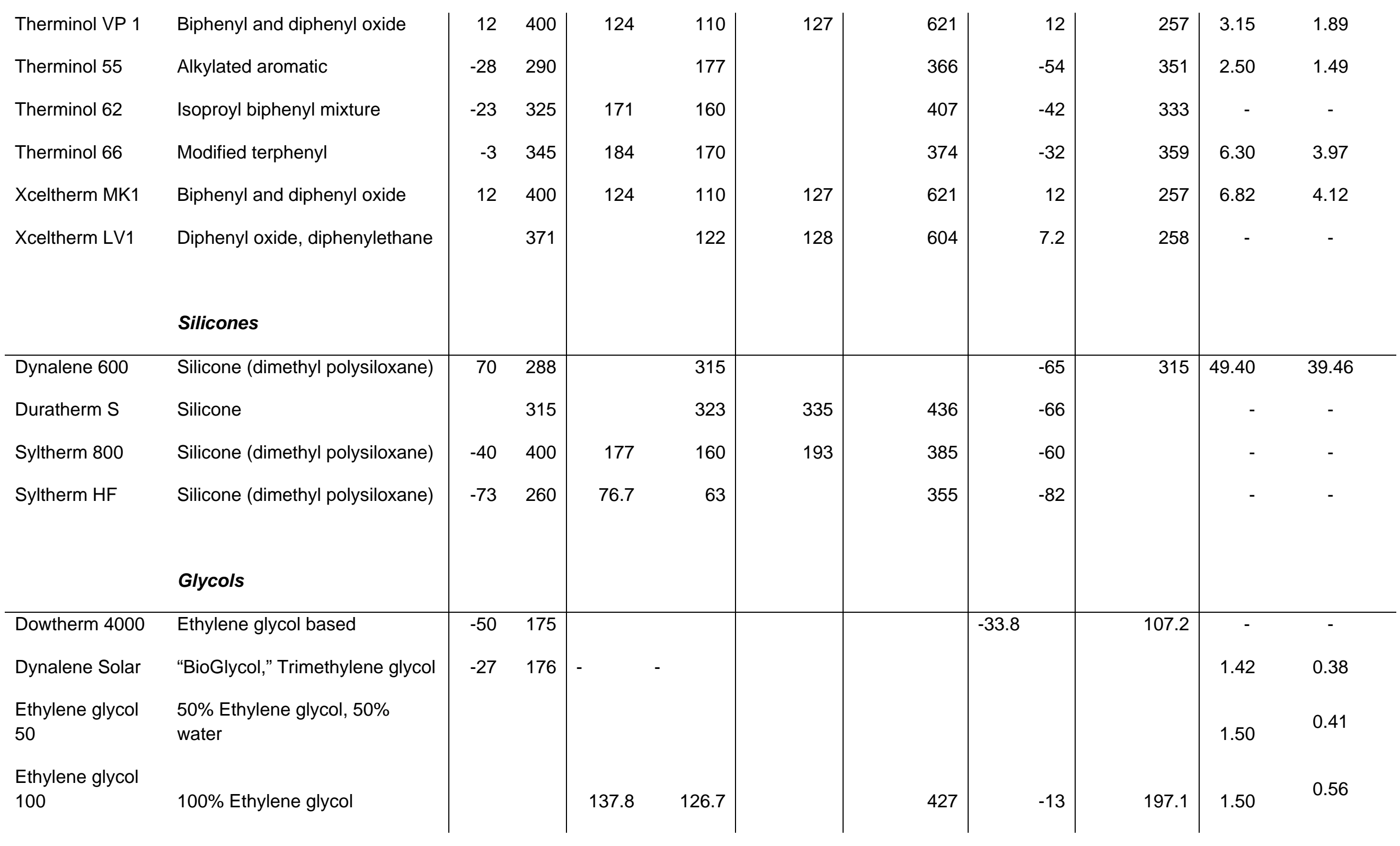




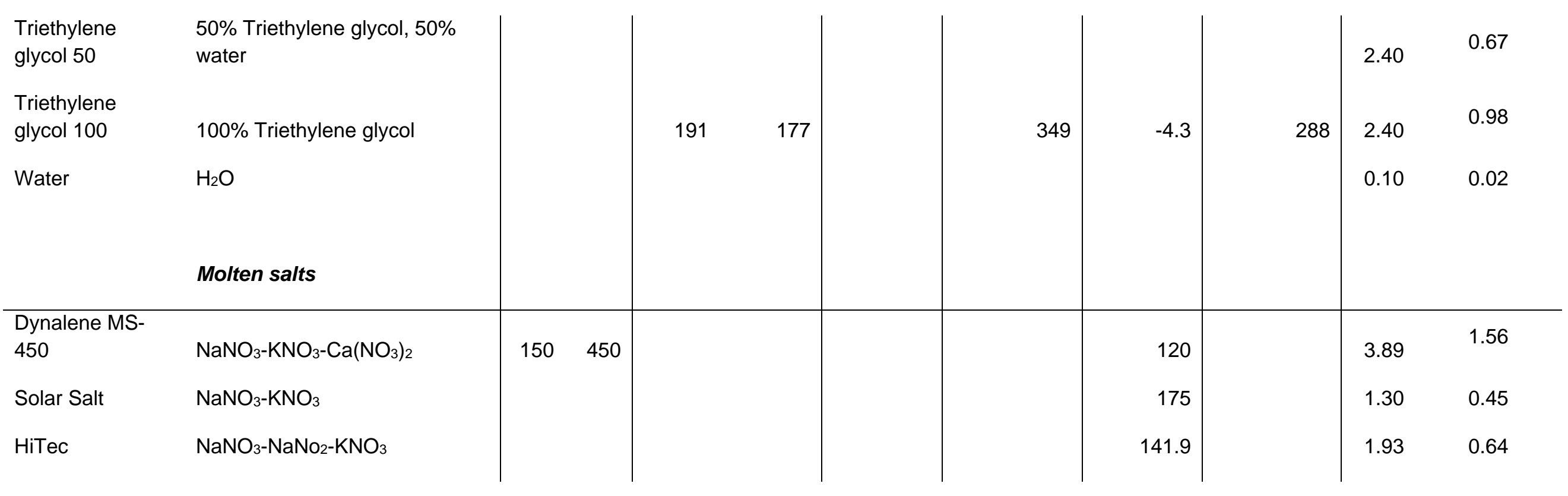




\section{Table A-2. Selected Thermodynamic Properties for All the Heat Transfer Fluids Considered in this Report}

\begin{tabular}{|c|c|c|c|c|c|c|c|c|c|c|c|c|c|c|c|c|c|c|c|}
\hline \multirow[b]{3}{*}{ Mineral oil } & \multicolumn{4}{|c|}{ Vapor pressure, $\mathrm{kPa}$} & \multicolumn{3}{|c|}{ Heat capacity, kJ/kg K } & \multicolumn{3}{|c|}{ Viscosity, $\mathrm{mm}^{2} / \mathrm{s}$} & \multicolumn{3}{|c|}{ Density, $\mathrm{kg} / \mathrm{m}^{3}$} & \multicolumn{3}{|c|}{ Conductivity, W/m K } & \multicolumn{3}{|c|}{ Volumetric heat cap, $\mathrm{kJ} / \mathrm{m}^{3} \mathrm{~K}$} \\
\hline & $25^{\circ} \mathrm{C}$ & $100^{\circ} \mathrm{C}$ & $200^{\circ} \mathrm{C}$ & Max. & $25^{\circ} \mathrm{C}$ & $100^{\circ} \mathrm{C}$ & $200^{\circ} \mathrm{C}$ & $25^{\circ} \mathrm{C}$ & $100^{\circ} \mathrm{C}$ & $200^{\circ} \mathrm{C}$ & $25^{\circ} \mathrm{C}$ & $100^{\circ} \mathrm{C}$ & $200^{\circ} \mathrm{C}$ & $25^{\circ} \mathrm{C}$ & $100^{\circ} \mathrm{C}$ & $200^{\circ} \mathrm{C}$ & $25^{\circ} \mathrm{C}$ & $100^{\circ} \mathrm{C}$ & $200^{\circ} \mathrm{C}$ \\
\hline & & & & & & & & & & & & & & & & & & & \\
\hline Calflo AF & 0.00 & 1.05 & 2.75 & 15.3 & 1.94 & 2.15 & 2.55 & 100 & 9.00 & 1.50 & 847 & 810 & 725 & 0.142 & 0.139 & 0.133 & 1,643 & 1,742 & 1,849 \\
\hline Calflo HTF & 0.00 & 0.74 & 1.93 & 11.4 & 1.94 & 2.15 & 2.45 & 100 & 9.00 & 2.00 & 862 & 825 & 750 & 0.143 & 0.140 & 0.133 & 1,672 & 1,774 & 1,838 \\
\hline Calflo FG & 0.00 & 0.84 & 2.20 & 14.3 & 1.91 & 2.10 & 2.50 & 100 & 8.00 & 2.00 & 845 & 795 & 710 & 0.137 & 0.133 & 0.127 & 1,614 & 1,670 & 1,775 \\
\hline Duratherm HTO & 0.00 & 0.00 & 0.33 & 9.70 & 1.85 & 2.12 & 2.40 & 81.3 & 6.40 & 1.57 & 819 & 770 & 705 & 0.137 & 0.133 & 0.160 & 1,516 & 1,632 & 1,692 \\
\hline Duratherm 600 & 0.00 & 0.00 & 0.22 & 8.66 & 1.91 & 2.20 & 2.43 & 83.0 & 6.50 & 1.60 & 836 & 787 & 721 & 0.140 & 0.136 & 0.131 & 1,593 & 1,731 & 1,752 \\
\hline Duratherm 630 & 0.00 & 0.00 & 0.32 & 15.0 & 1.95 & 2.20 & 2.52 & 87.4 & 6.85 & 1.68 & 862 & 810 & 742 & 0.144 & 0.140 & 0.134 & 1,679 & 1,782 & 1,870 \\
\hline Duratherm HF & 0.00 & 0.00 & 0.16 & 36.8 & 1.85 & 1.98 & 2.16 & 241 & 12.5 & 2.00 & 863 & 836 & 799 & 0.149 & 0.148 & 0.146 & 1,597 & 1,655 & 1,726 \\
\hline Marlotherm FG & 0.00 & 0.00 & 1.97 & 32.2 & 1.94 & 2.25 & 2.67 & 20.1 & 3.60 & 1.00 & 841 & 802 & 742 & 0.136 & 0.131 & 0.123 & 1,632 & 1,805 & 1,981 \\
\hline Marlotherm LH & 0.00 & 0.22 & 13.1 & 483 & 1.64 & 1.88 & 2.22 & 5.07 & 1.10 & 0.47 & 984 & 936 & 856 & 0.133 & 0.122 & 0.111 & 1,614 & 1,760 & 1,900 \\
\hline Marlotherm N & 0.00 & 0.00 & 0.70 & 39.0 & 1.91 & 2.26 & 2.62 & 56.0 & 3.00 & 0.87 & 880 & 823 & 755 & 0.136 & 0.129 & 0.121 & 1,681 & 1,860 & 1,978 \\
\hline Marlotherm SH & 0.00 & 0.00 & 0.50 & 86.0 & 1.57 & 1.85 & 2.22 & 24.0 & 3.10 & 0.92 & 1,034 & 987 & 915 & 0.130 & 0.120 & 0.107 & 1,623 & 1,826 & 2,031 \\
\hline Marlotherm XD & 0.00 & 3.8 & 98.4 & 254 & 2.16 & 2.47 & 2.99 & 1.38 & 0.61 & 0.17 & 768 & 705 & 628 & 0.120 & 0.104 & 0.080 & 1,659 & 1,741 & 1,878 \\
\hline Multitherm OG 1 & 0.00 & 0.00 & 0.13 & 18.6 & 1.95 & 2.10 & 2.47 & 50.0 & 4.60 & 1.30 & 855 & 816 & 763 & 0.137 & 0.136 & 0.132 & 1,667 & 1,715 & 1,885 \\
\hline Multitherm PG 1 & 0.00 & 0.00 & 0.09 & 3.68 & 1.92 & 2.17 & 2.53 & 29.0 & 2.98 & 0.80 & 877 & 840 & 798 & 0.132 & 0.127 & 0.120 & 1,684 & 1,823 & 2,019 \\
\hline Multitherm 503 & 0.00 & 0.01 & 2.90 & 20.0 & 2.14 & 2.40 & 2.79 & 5.50 & 1.26 & 0.45 & 788 & 741 & 676 & 0.141 & 0.136 & 0.130 & 1,686 & 1,778 & 1,886 \\
\hline Paratherm HE & 0.00 & 0.00 & 0.12 & 6.00 & 1.90 & 2.30 & 2.70 & 87.0 & 6.40 & 1.60 & 857 & 811 & 751 & 0.127 & 0.121 & 0.112 & 1,628 & 1,865 & 2,028 \\
\hline Paratherm NF & 0.00 & 0.02 & 2.70 & 43.0 & 1.80 & 2.30 & 2.80 & 30.8 & 3.78 & 0.94 & 880 & 843 & 779 & 0.108 & 0.102 & 0.094 & 1,584 & 1,939 & 2,181 \\
\hline Petrotherm & 0.00 & 0.74 & 1.93 & 11.4 & 1.93 & 2.17 & 2.50 & 30.0 & 5.00 & 2.00 & 862 & 816 & 752 & 0.143 & 0.139 & 0.133 & 1,664 & 1,771 & 1,880 \\
\hline
\end{tabular}




\begin{tabular}{|c|c|c|c|c|c|c|c|c|c|c|c|c|c|c|c|c|c|c|c|}
\hline Xceltherm CA & 0.00 & 0.00 & 2.90 & 10.3 & 2.00 & 2.50 & 2.90 & 50.0 & 5.00 & 1.00 & 820 & 800 & 750 & 0.133 & 0.127 & 0.121 & 1,640 & 2,000 & 2,175 \\
\hline Xceltherm 600 & 0.00 & 0.0138 & 1.07 & 24.5 & 2.01 & 2.29 & 2.61 & 30.9 & 2.73 & 0.84 & 848 & 801 & 743 & 0.136 & 0.129 & 0.122 & 1,707 & 1,829 & 1,936 \\
\hline Therminol XP & 0.00 & 0.02 & 1.71 & 43.0 & 1.84 & 2.18 & 2.60 & 51.0 & 4.06 & 1.10 & 876 & 827 & 761 & 0.115 & 0.109 & 0.099 & 1,612 & 1,803 & 1,979 \\
\hline \multicolumn{20}{|l|}{ Synthetic fluids } \\
\hline Dowtherm A & 0.0026 & 0.60 & 24.0 & 1060 & 1.59 & 1.80 & 2.08 & 3.71 & 0.97 & 0.39 & 1,056 & 995 & 907 & 0.138 & 0.126 & 0.110 & 1,675 & 1,791 & 1,886 \\
\hline Dowtherm G & 0.00 & 0.00 & 10.0 & 370 & 1.55 & 1.81 & 2.16 & 11.0 & 1.92 & 0.62 & 1,040 & 989 & 911 & 0.126 & 0.118 & 0.106 & 1,612 & 1,788 & 1,967 \\
\hline Dowtherm Q & 0.00 & 5.00 & 17.0 & 320 & 1.78 & 1.90 & 2.21 & 4.70 & 0.85 & 0.31 & 965 & 905 & 829 & 0.122 & 0.111 & 0.097 & 1,718 & 1,720 & 1,831 \\
\hline Dowtherm 4000 & 0.00 & 0 & & & 3.25 & 3.55 & - & 3.70 & 0.70 & & 1,080 & 1,030 & - & 0.380 & 0.414 & - & 3,510 & 3,657 & \\
\hline Dynalene SF & \multicolumn{4}{|c|}{$?$} & 1.98 & 2.26 & 2.63 & 34.3 & 4.13 & 1.32 & 874 & 823 & 756 & 0.134 & 0.129 & 0.121 & 1,731 & 1,859 & 1,985 \\
\hline Paratherm HR & 0.00 & 0.04 & 2.89 & 145 & 1.90 & 2.10 & 2.30 & 22.0 & 2.30 & 0.86 & 940 & 893 & 824 & 0.117 & 0.111 & 0.103 & 1,786 & 1,875 & 1,895 \\
\hline Paratherm HT & 0.00 & 0.02 & 1.70 & 90.0 & 1.70 & 1.90 & 2.20 & 79.0 & 4.50 & 0.94 & 1,003 & 961 & 892 & 0.115 & 0.109 & 0.100 & 1,705 & 1,826 & 1,962 \\
\hline Therminol VP 1 & 0.0026 & 0.60 & 27.2 & 1150 & 1.57 & 1.79 & 2.06 & 3.37 & 0.94 & 0.42 & 1,059 & 995 & 909 & 0.136 & 0.127 & 0.113 & 1,663 & 1,781 & 1,873 \\
\hline Therminol 55 & 0.00 & 0.03 & 2.15 & 27.2 & 1.93 & 2.19 & 2.54 & 38.2 & 3.52 & 1.00 & 868 & 818 & 748 & 0.128 & 0.119 & 0.107 & 1,675 & 1,791 & 1,900 \\
\hline Therminol 62 & 0.00 & 0.06 & 3.49 & 86.5 & 1.96 & 2.14 & 2.36 & 20.8 & 2.52 & 0.72 & 951 & 897 & 820 & 0.123 & 0.116 & 0.106 & 1,864 & 1,920 & 1,935 \\
\hline Therminol 66 & 0.00 & 0.05 & 2.23 & 78.2 & 1.58 & 1.84 & 2.19 & 88.8 & 3.77 & 0.97 & 1,005 & 955 & 885 & 0.117 & 0.114 & 0.106 & 1,588 & 1,757 & 1,938 \\
\hline Xceltherm MK1 & 0.00 & 0.60 & 27.3 & 1080 & 1.57 & 1.79 & 2.06 & 3.37 & 0.94 & 0.42 & 1,059 & 995 & 910 & 0.136 & 0.127 & 0.113 & 1,657 & 1,778 & 1,874 \\
\hline Xceltherm LV1 & 0.0028 & 0.56 & 25.9 & 715 & 1.59 & 1.81 & 2.09 & 4.49 & 1.12 & 0.44 & 1,058 & 993 & 910 & 0.135 & 0.126 & 0.112 & 1,681 & 1,801 & 1,902 \\
\hline \multicolumn{20}{|l|}{ Silicones } \\
\hline Dynalene 600 & & & & & - & 1.43 & 1.62 & - & 33.8 & 13.3 & - & 875 & 776 & - & 0.141 & 0.123 & & 1,252 & 1,256 \\
\hline Duratherm S & 0.00 & 0 & 0.12 & 6.85 & 1.69 & 1.83 & 2.02 & 46.5 & 16.7 & 7.30 & 961 & 942 & 915 & 0.136 & 0.124 & 0.110 & 1,624 & 1,724 & 1,848 \\
\hline
\end{tabular}




\begin{tabular}{|c|c|c|c|c|c|c|c|c|c|c|c|c|c|c|c|c|c|c|c|}
\hline Syltherm 800 & 0.05 & 5.5 & 94.6 & 1373 & 1.60 & 1.74 & 1.92 & 11.0 & 3.05 & 1.05 & 930 & 863 & 773 & 0.135 & 0.120 & 0.101 & 1,488 & 1,502 & 1,482 \\
\hline Syltherm HF & 0.00 & 6 & 102 & 274 & 1.71 & 1.88 & 2.13 & 1.58 & 0.67 & 0.31 & 861.65 & 785 & 685 & 0.105 & 0.084 & 0.061 & 1,471 & 1,476 & 1,459 \\
\hline \multicolumn{20}{|l|}{ Glycols } \\
\hline Dynalene Solar & & & & & 3.60 & 4.02 & & & & & 1,040 & 985 & & 0.365 & 0.382 & & 3,744 & 3,960 & 0 \\
\hline Ethylene glycol 50 & 3.00 & 86 & $1,123.4$ & $1,123.4$ & 3.49 & 3.72 & 4.02 & 3.37 & 0.68 & 0.24 & 1,062 & 1,010 & 914 & 0.410 & 0.370 & 0.290 & 3,701 & 3,754 & 3,676 \\
\hline Ethylene glycol 100 & 0.00 & 3 & 111 & 111 & 2.40 & 2.77 & 3.27 & 18.8 & 2.00 & 0.43 & 1,111 & 1,056 & 965 & 0.290 & 0.230 & 0.150 & 2,670 & 2,929 & 3,156 \\
\hline Triethylene glycol & & & & & & & & & & & & & & & & & & & \\
\hline 50 & 4.00 & 97 & 1,387 & 5,301 & 3.36 & 3.65 & 4.12 & 6.15 & 0.92 & - & 1,072 & 1,018 & 935 & 0.400 & 0.400 & 0.410 & 3,602 & 3,716 & 3,851 \\
\hline $\begin{array}{l}\text { Triethylene glycol } \\
100\end{array}$ & 0.00 & 0 & 7 & 73 & 2.18 & 2.61 & 3.19 & 48.9 & 3.31 & - & 1,122 & 1,062 & 976 & 0.230 & 0.190 & 0.140 & 2,446 & 2,776 & 3,115 \\
\hline Water & 3.20 & 101.3 & 1,550 & - & 4.18 & 4.22 & 4.51 & 0.90 & 0.29 & - & 997.1 & 958 & 864 & 0.607 & 0.679 & - & 4,168 & 4,042 & 3,897 \\
\hline \multicolumn{20}{|l|}{ Molten salts } \\
\hline Dynalene MS-450 & - & - & - & - & - & - & 1.26 & - & - & 20.4 & - & - & 1,989 & - & - & 0.450 & - & - & 2,496 \\
\hline Solar Salt & - & - & - & - & - & - & 1.48 & - & - & 16.7 & - & - & 1,963 & - & - & 0.450 & - & - & 2,901 \\
\hline HiTec & - & - & - & - & - & - & 1.56 & - & - & 3.77 & - & - & 1,933 & - & - & 0.480 & - & - & 3,016 \\
\hline
\end{tabular}




\section{Appendix B}

The first-law efficiency is

$\eta_{1, o}=\frac{W_{o}}{Q}$

The hybrid first-law efficiency is

$\eta_{1}=\frac{W}{Q+Q_{\text {sol }}}$

The solar conversion efficiency is

$\eta_{\mathrm{sol}}=\frac{W-W_{o}}{Q_{\mathrm{sol}}}$

The first law may therefore be written as

$\eta_{1}=\frac{W+\eta_{\mathrm{sol}} Q_{\mathrm{sol}}}{Q+Q_{\mathrm{sol}}}$

Differentiating with respect to $Q_{\text {sol }}$ leads to

$\frac{\partial \eta_{1}}{\partial Q_{\mathrm{sol}}}=\frac{\eta_{\mathrm{sol}} Q-W_{o}}{\left(Q+Q_{\mathrm{sol}}\right)^{2}}$

In order for the first-law efficiency to increase with solar heat addition, the first derivative must be greater than zero. This leads to the condition

$\eta_{\mathrm{sol}}>\frac{W_{o}}{Q}=\eta_{1, o}$ 